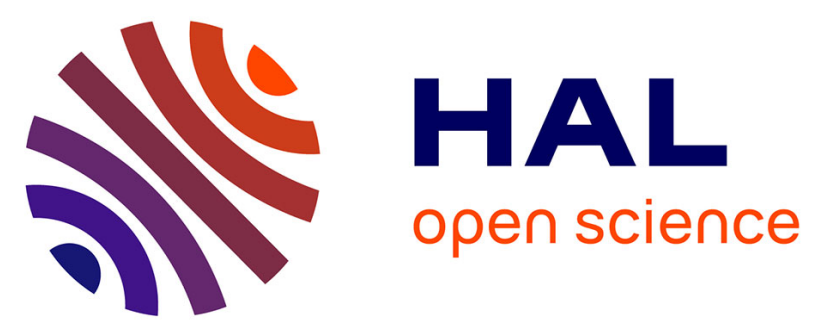

\title{
DNA Methylation in Ensifer Species during Free-Living Growth and during Nitrogen-Fixing Symbiosis with Medicago spp.
}

George C Dicenzo, Lisa Cangioli, Quentin Nicoud, Janis Cheng, Matthew Blow, Nicole Shapiro, Tanja Woyke, Emanuele Biondi, Benoît Alunni, Alessio Mengoni, et al.

\section{To cite this version:}

George C Dicenzo, Lisa Cangioli, Quentin Nicoud, Janis Cheng, Matthew Blow, et al.. DNA Methylation in Ensifer Species during Free-Living Growth and during Nitrogen-Fixing Symbiosis with Medicago spp.. mSystems, 2022, 10.1128/mSystems.01092-21 . hal-03528188

\section{HAL Id: hal-03528188 \\ https://hal.science/hal-03528188}

Submitted on 17 Jan 2022

HAL is a multi-disciplinary open access archive for the deposit and dissemination of scientific research documents, whether they are published or not. The documents may come from teaching and research institutions in France or abroad, or from public or private research centers.
L'archive ouverte pluridisciplinaire HAL, est destinée au dépôt et à la diffusion de documents scientifiques de niveau recherche, publiés ou non, émanant des établissements d'enseignement et de recherche français ou étrangers, des laboratoires publics ou privés. 


\title{
DNA Methylation in Ensifer Species during Free-Living Growth and during Nitrogen-Fixing Symbiosis with Medicago spp.
}

\author{
(D) George C. diCenzo, ${ }^{\text {a,b }}$ (D) Lisa Cangioli, ${ }^{b}$ Quentin Nicoud, ${ }^{c}$ (D) Janis H. T. Cheng, ${ }^{a}$ (D) Matthew J. Blow, ${ }^{d}$ Nicole Shapiro, ${ }^{d}$ \\ (D) Tanja Woyke, ${ }^{\mathrm{d}}$ (D) Emanuele G. Biondi, ${ }^{\mathrm{c}}$ (D) Benoît Alunni, ${ }^{\mathrm{c}}$ (D) Alessio Mengoni, ${ }^{\text {b }}$ (D) Peter Mergaert ${ }^{\mathrm{c}}$
}

aDepartment of Biology, Queen's University, Kingston, Ontario, Canada

bDepartment of Biology, University of Florence, Florence, Italy

cUniversité Paris-Saclay, CEA, CNRS, Institute for Integrative Biology of the Cell, Gif-sur-Yvette, France

dU.S. Department of Energy Joint Genome Institute, Berkeley, California, USA

Peter Mergaert and Alessio Mengoni contributed equally to this work. Author order was determined alphabetically.

ABSTRACT Methylation of specific DNA sequences is ubiquitous in bacteria and has known roles in immunity and regulation of cellular processes, such as the cell cycle. Here, we explored DNA methylation in bacteria of the genus Ensifer, including its potential role in regulating terminal differentiation during nitrogen-fixing symbiosis with legumes. Using single-molecule real-time sequencing, six genome-wide methylated motifs were identified across four Ensifer strains, five of which were strain-specific. Only the GANTC motif, recognized by the cell cycle-regulated CcrM methyltransferase, was methylated in all strains. In actively dividing cell cultures, methylation of GANTC motifs increased progressively from the ori to ter regions in each replicon, in agreement with a cell cycle-dependent regulation of CcrM. In contrast, there was near full genome-wide GANTC methylation in the early stage of symbiotic differentiation. This was followed by a moderate decrease in the overall extent of methylation and a progressive decrease in chromosomal GANTC methylation from the ori to ter regions in later stages of differentiation. Based on these observations, we suggest that CcrM activity is dysregulated and constitutive during terminal differentiation, which we hypothesize is a driving factor for endoreduplication of terminally differentiated bacteroids.

IMPORTANCE Nitrogen fixation by rhizobia in symbiosis with legumes is economically and ecologically important. The symbiosis can involve a complex bacterial transformationterminal differentiation-that includes major shifts in the transcriptome and cell cycle. Epigenetic regulation is an important regulatory mechanism in diverse bacteria; however, the roles of DNA methylation in rhizobia and symbiotic nitrogen fixation have been poorly investigated. We show that aside from cell cycle regulation, DNA methyltransferases are unlikely to have conserved roles in the biology of bacteria of the genus Ensifer. However, we present evidence consistent with an interpretation that the cell cycle methyltransferase CcrM is dysregulated during symbiosis, which we hypothesize may be a key factor driving the cell cycle switch in terminal differentiation required for effective symbioses.

KEYWORDS rhizobia, symbiotic nitrogen fixation, DNA methylation, cell cycle regulation, CcrM

ethylation of genomic DNA is a pervasive phenomenon found in eukaryotes (1-3), archaea (4), and bacteria $(4,5)$. The biological roles of DNA methylation are most extensively studied in mammals, where it contributes to normal development and disease via its impact on gene expression (6). In bacteria, DNA methylation is best known for its role in restriction-modification (R-M) systems that are thought to provide defense against phage
Editor Davide Bulgarelli, University of Dundee Copyright $\odot 2022$ diCenzo et al. This is an open-access article distributed under the terms of the Creative Commons Attribution 4.0 International license.

Address correspondence to George C. diCenzo george.dicenzo@queensu.ca.

The authors declare no conflict of interest.

Received 2 September 2021

Accepted 9 December 202

Published 4 January 2022 
infection and limit horizontal gene transfer through the degradation of invading nonmethylated DNA (7). Several methyltransferases (MTases) of R-M systems have also been implicated in phase variation in pathogens through modulating gene expression (8). A recent study of over 200 bacterial and archaeal species identified orphan MTases not belonging to R-M systems in nearly half of the genomes (4). To date, biological functions have been attributed to very few orphan MTases, namely, the Dam MTase of the Gammaproteobacteria and the CcrM MTase of the Alphaproteobacteria (9). The Dam MTase of Escherichia coli is notable for its role in regulation of DNA replication $(10,11)$ and DNA repair $(12)$ by modulating the activity of other DNA-binding proteins. The CcrM MTase was first identified in Caulobacter crescentus (13), with homologs since identified in diverse Alphaproteobacteria $(14,15)$. CcrM activity was shown to be cell cycle regulated in C. crescentus and Agrobacterium tumefaciens $(13,16)$, leading to methylation of its cognate DNA motif (the pentanucleotide GANTC) specifically during a short period at the end of DNA replication. This leads to a switching of GANTC sites between fully methylated (methylated on both strands) and hemi-methylated (methylated only on the template strand) as a result of DNA replication (17), which serves to modulate gene expression in a cell cycle-dependent fashion (18-20). Over- and underexpression of ccrM result in defects in DNA replication and cell division $(14,16,19)$, while its complete loss is lethal under some conditions.

The rhizobia are a polyphyletic group of Alphaproteobacteria and Betaproteobacteria that can both live free in the soil and enter into an endosymbiotic interaction with legumes (21). This interaction begins following an exchange of signals between the free-living partners (22), and it culminates in the formation of a new organ known as a root nodule, within which the cytoplasm of plant cells contain thousands of $\mathrm{N}_{2}$-fixing bacteria called bacteroids. Bacteroid formation results in the differential expression of more than a thousand genes $(23,24)$ and global changes in cellular metabolism (25). In legumes of the inverted-repeat lacking clade (IRLC) and the dalbergioid clade of the family Papilionoideae, bacteroid development involves an additional process of terminal differentiation $(26,27)$; in other legume clades, bacteroid differentiation is less pronounced and is reversible. Terminal bacteroid development, in contrast to reversible bacteroid formation, involves cell enlargement (bacteroids are 5- to 10-fold longer than their free-living counterparts) and genome endoreduplication (resulting in up to 24 copies of the genome per cell), indicative of a cell cycle transition occurring during differentiation (26). Indeed, the correct expression of cell cycle regulators in Ensifer (syn. Sinorhizobium) meliloti, a symbiont of Medicago species of the IRLC, is essential for the formation of functional bacteroids $(28,29)$, while overexpression of CcrM or disruption of the master cell cycle regulator CtrA can give rise to bacteroid-like morphology in free-living cells (14, 30). Additionally, mutants in the $E$. meliloti cell cycle regulators divJ, cbrA, and $c p d R 1$, encoding three negative regulators of $\mathrm{CtrA}$, form nonfunctional nodules in which bacteroids do not differentiate properly $(28,29,31)$, and genes encoding several cell cycle regulators (including CcrM) are strongly downregulated in bacteroids (24). The differentiation and cell cycle switch of bacteroids is controlled by the legume host through the production of a large family of peptides, known as nodule-specific cysteine-rich (NCR) peptides (32-34).

Multiple studies have provided evidence that changes in the methylation status of the DNA of legume nodule cells contribute to symbiotic development (35-37). Conversely, it remains unknown if methylation of rhizobium DNA contributes to the regulation of $\mathrm{N}_{2}$-fixation or bacteroid development. We are aware of only one study (38) comparing DNA methylation of a rhizobium (Bradyrhizobium diazoefficiens USDA110) between free-living and symbiotic states (soybean nodules) and comparing these changes with differential expression data. Intriguingly, the authors identified a DNA motif that was methylated specifically in bacteroids (38). However, no clear evidence was presented that methylation of this (or any other) motif is involved in transcriptional regulation, and the number of genes both differentially expressed and differentially methylated in bacteroids did not appear to be different than expected by chance. While these data may suggest that DNA methylation does not play a major role in regulating $\mathrm{N}_{2}$-fixation by rhizobia, they do not address the role of DNA methylation in terminal bacteroid differentiation, as $B$. diazoefficiens undergoes reversible differentiation in soybean nodules (39).

Here, we use Pacific Biosciences single-molecule real-time (SMRT) sequencing to detect genome-wide patterns of DNA methylation in four strains belonging to the genus Ensifer. 
TABLE 1 Methylated motifs identified in this study

\begin{tabular}{|c|c|c|c|}
\hline Motif $^{a}$ & Type $^{b}$ & Count $^{c}$ & $\begin{array}{l}\text { Frequency } \\
\text { (motifs/kb) }\end{array}$ \\
\hline \multicolumn{4}{|l|}{ E. meliloti 2011} \\
\hline GANTC & $\mathrm{m} 6 \mathrm{~A}$ & 11,169 & 1.67 \\
\hline \multicolumn{4}{|l|}{ CTNAG } \\
\hline RCGCCTC & $\mathrm{m} 4 \mathrm{C}$ & 3,943 & 0.59 \\
\hline \multicolumn{4}{|l|}{ YGCGGAG } \\
\hline CGCA(N5)GTG & $\mathrm{m} 6 \mathrm{~A}$ & 1,085 & 0.16 \\
\hline \multicolumn{4}{|l|}{ GCGT(N5)CAC } \\
\hline \multicolumn{4}{|l|}{ E. meliloti FSM-MA } \\
\hline GANTC & $\mathrm{m} 6 \mathrm{~A}$ & 11,215 & 1.67 \\
\hline \multicolumn{4}{|l|}{ CTNAG } \\
\hline TCGA(N8)TCGA & $\mathrm{m} 6 \mathrm{~A}$ & 2,612 & 0.39 \\
\hline \multicolumn{4}{|l|}{ AGCT(N8)AGCT } \\
\hline \multicolumn{4}{|l|}{ E. fredii NGR234 } \\
\hline GANTC & $\mathrm{m} 6 \mathrm{~A}$ & 11,111 & 1.61 \\
\hline \multicolumn{4}{|l|}{ CTNAG } \\
\hline CAGA(N7)GTTG & $\mathrm{m} 6 \mathrm{~A}$ & 188 & 0.03 \\
\hline \multicolumn{4}{|l|}{ GTCT(N7)CAAC } \\
\hline \multicolumn{4}{|l|}{ E. adhaerens OV14 } \\
\hline GANTC & $\mathrm{m} 6 \mathrm{~A}$ & 8,475 & 1.10 \\
\hline \multicolumn{4}{|l|}{ CTNAG } \\
\hline WNCCGATG & $\mathrm{m} 6 \mathrm{~A}$ & 4,596 & 0.60 \\
\hline WNGGCTAC & & & \\
\hline
\end{tabular}

aThe methylated nucleotides are indicated in boldface font.

${ }^{b}$ Indicates whether the modification is an $\mathrm{N}^{6}$-methyladenoside (m6A) or $\mathrm{N}^{4}$-methylcytosine ( $\left.\mathrm{m} 4 \mathrm{C}\right)$.

The total times the motif appears in the genome, regardless of methylation status.

Our results indicate that DNA methylation is poorly conserved across the genus, and interestingly, they reveal that the pattern of GANTC methylation in $\mathrm{N}_{2}$-fixing bacteroids differs from that of free-living cells. Based on these data, we hypothesize that constitutive activation of the CcrM MTase may be a contributing factor driving terminal differentiation.

\section{RESULTS}

The methylomes of the genus Ensifer. Our experimental design, as summarized in Materials and Methods and Fig. S1 (at doi.org/10.6084/m9.figshare.16556205), was developed to support an investigation into multiple potential roles of DNA methylation in plantassociated bacteria from the genus Ensifer through the use of SMRT sequencing. This was accomplished by (i) including DNA samples isolated from phylogenetically diverse wild-type strains, (ii) examining DNA methylation in a single strain across multiple conditions (exponential-phase growth versus stationary phase; growth with sucrose versus growth with succinate), (iii) investigating the impact of a large-scale genome reduction on DNA methylation patterns, and (iv) isolating DNA from bacteroids purified from legume nodules.

We began with base modification analyses of four wild-type strains from three species, including three nodule-forming strains (E. meliloti Rm2011, E. meliloti FSM-MA, Ensifer fredii NGR234) and one plant-associated, nonsymbiotic strain (Ensifer adhaerens OV14). To ensure consistency, all strains were grown to mid-exponential phase in a common minimal medium with succinate as the carbon source. A total of six methylated motifs were identified, of which five were m6A modifications and one was a m4C modification (Table 1). Five of the six motifs were methylated specifically in one strain. Only the GANTC motif, recognized by the highly conserved cell cycle-regulated CcrM methyltransferase $(13,14)$, was methylated in all four strains. To further examine the conservation, or lack thereof, of DNA modification across the genus Ensifer, we examined the distribution of methyltransferases in the model species E. meliloti. Based on gene annotations, we identified 24 genes encoding putative MTases in a previous pangenome analysis of $20 \mathrm{E}$. meliloti strains (Table S1 at doi.org/10 $.6084 / \mathrm{m} 9$. figshare.16556205) (40). Of these 24 genes, only 1 (ccrM) was found in all 20 strains, while 4 were found in 2 strains and 19 were found in a single strain. These results 

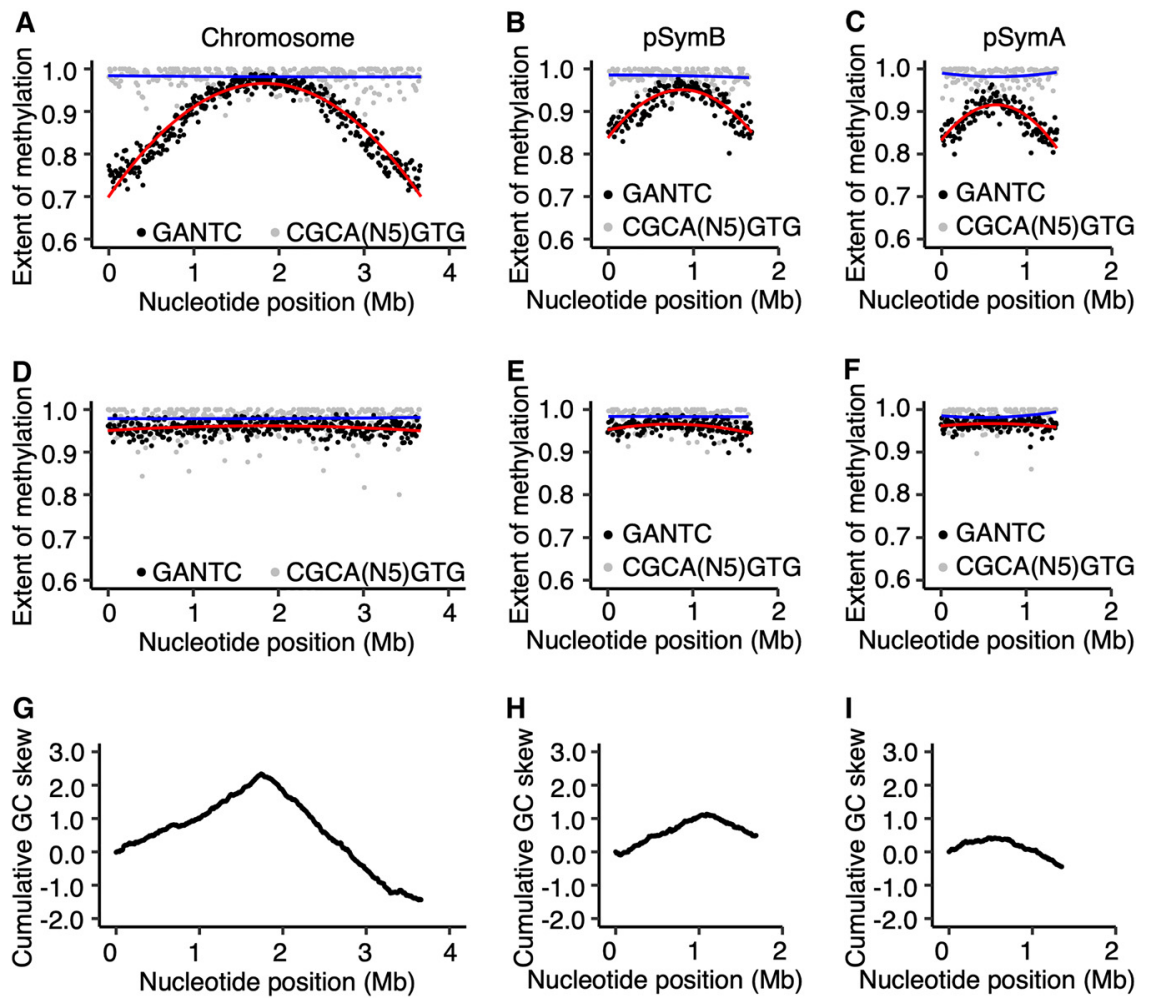

FIG 1 Genome-wide DNA methylation of E. meliloti Rm2011. (A to F) The extent of methylation is shown, using a 10-kb sliding window, of GANTC sites (black) and CGCA $\left(\mathrm{N}_{5}\right)$ GTG sites (gray) across the chromosome ( $A$ and $D), p S y m B(B$ and $E$ ), and pSymA ( $C$ and $F$ ) replicons of exponential phase ( $A$ to $C$ ) or early stationary phase (D to F) E. meliloti Rm2011. Averages from three biological replicates are shown. The red (GANTC) and blue [CGCA( $\left.N_{5}\right)$ GTG] lines are polynomial regression lines calculated in R using the "rlm" method and the formula " $y \sim \operatorname{poly}(x, 2)$." (G and I) Cumulative GC skews, shown using a 10-kb sliding window, across the E. meliloti Rm2011 chromosome (G), pSymB (H), and pSymA (I) replicons.

suggest that DNA methylation is unlikely to play a conserved role in the genus Ensifer aside from cell cycle control via CcrM-mediated methylation and phage defense.

None of the motifs methylated in E. meliloti Rm2011 were enriched in the promoter regions of genes previously shown to be differentially expressed when grown with glucose versus succinate (41). Similarly, except for the GANTC motif as discussed below, no global effect of carbon source (sucrose [glycolytic] versus succinate [gluconeogenic]) was observed on the DNA methylation pattern of E. meliloti Rm2011 (Fig. S2 at doi.org/10.6084/m9.figshare .16556205). Moreover, no global differences in DNA methylation were detected between $E$. meliloti Rm2011 and RmP3496, an Rm2011 derivative lacking the pSymA and pSymB replicons that together account for $45 \%$ of the genome content of E. meliloti (42) (Fig. S3 at doi.org/10 $.6084 / \mathrm{m} 9$. figshare.16556205). These results suggest that at least under the tested conditions, most DNA MTases are not likely to have a regulatory function in the genus Ensifer, although they could play regulatory roles in other environments.

Cell cycle regulation by the CcrM methyltransferase. A progressive increase in the extent of methylation (here defined as the estimated fraction of reads mapping to a motif that were methylated) of GANTC sites was observed from the ori to ter regions of the chromosomes of all four strains during mid-exponential growth (Fig. 1, and Fig. S4 to S6 at doi.org/10 $.6084 /$ m9.figshare.16556205). There was a local drop in GANTC methylation around the 1.5-Mb mark in the E. meliloti FSM-MA chromosome (Fig. S4 at doi.org/10.6084/m9.figshare .16556205); however, this was seen in only two of three replicates and corresponded to a region of high sequencing depth (Fig. S7 at doi.org/10.6084/m9.figshare.16556205), suggesting the result is a sequencing artifact. In contrast to exponential-phase cultures, GANTC sites displayed near full methylation (averaging 95\%) across the genome during early stationary phase, while all other motifs displayed near full methylation (averaging 95 to $99 \%$ ) across 
A

birth division
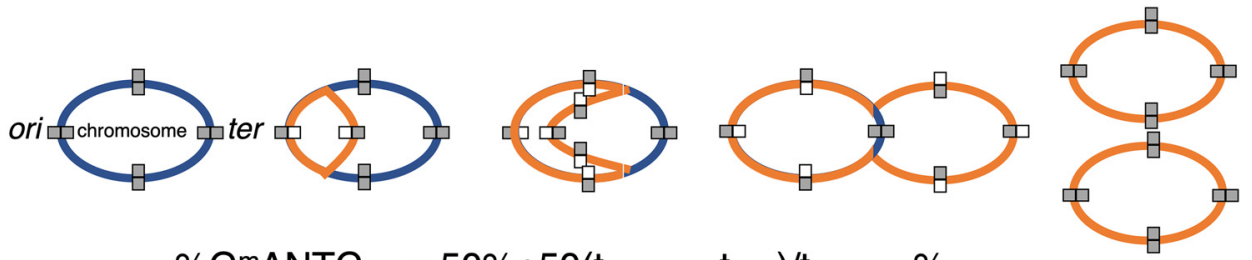

$\% \mathrm{GmANTC}_{\text {ori }} \approx 50 \%+50\left(\mathrm{t}_{\text {cell cycle }} \mathrm{t}_{\text {rep }}{ }^{\star}\right) / \mathrm{t}_{\text {cell cycle }} \%$
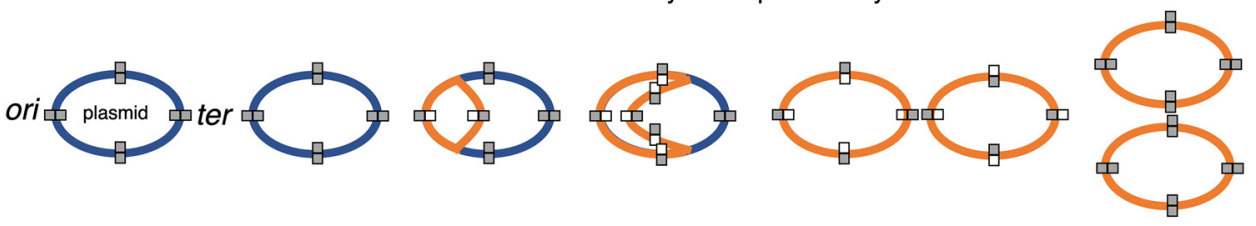

B

\section{CorM}
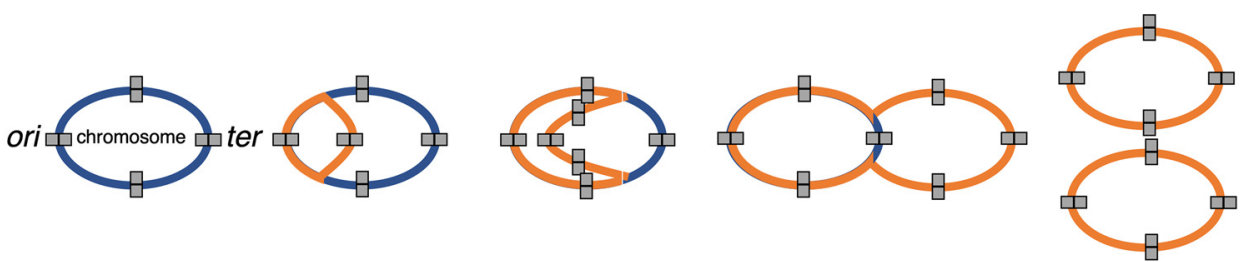

C
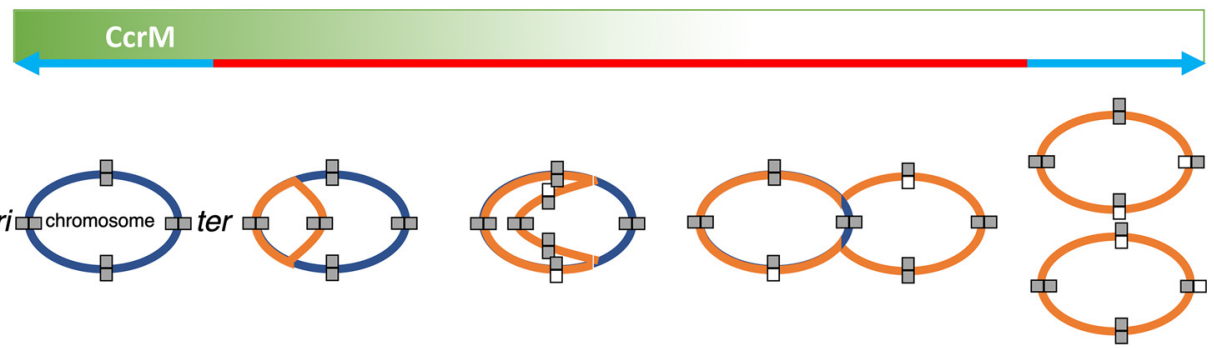

FIG 2 Model describing the GANTC methylation patterns observed in cultures and bacteroids. In all panels, the replication progression and methylation status of the circular chromosome and a megaplasmid are depicted during the cell cycle progression from cell birth until division. The replicons at cell birth are in dark blue, and the newly replicated DNA is in orange. Full-gray rectangles indicate GANTC sites that are in the fully methylated state, while gray/white rectangles indicate the hemimethylated state. The green boxes along the top indicate when CcrM is known or postulated to be active during the cell cycle, while the blue/red line indicates the relevant cell cycle phases; red is the S-phase or genome replication phase and blue is the gap phases and division. (A) The activity of CcrM in free-living cells during exponential growth. The formula expresses the extent of methylation at the origin (ori) of replication in an asynchronous bacterial population in culture. (B) The proposed activity of CcrM at an early stage of bacteroid differentiation, during which we suggest that the activity of CcrM is extended to also include the replication phase of the cell cycle. (C) The proposed activity of CcrM at a late stage of bacteroid differentiation, during which we suggest that there is a drop in CcrM activity during the last chromosome replication cycle of the endoreduplication process. The iconography of the illustrations is based on Fig. 1 of Mohapatra et al. (43). Refer to Fig. S22 at doi.org/10.6084/ m9.figshare.16556205 for a version of this figure with a more detailed legend.

the genome regardless of growth state (Fig. 1, and Fig. S4 to S6 at doi.org/10.6084/m9 .figshare.16556205). The observed pattern of GANTC methylation indicates a progressive switch from fully to hemi-methylated states as DNA replication proceeds (model provided as Fig. 2), confirming that the CcrM methyltransferase of the family Rhizobiaceae is cell cycle regulated as demonstrated in $C$. crescentus $(13,17,43)$. Interestingly, the genome-wide pattern of GANTC methylation displayed a smaller variation in the extent of methylation from 
the ori to ter regions in E. meliloti Rm2011 when grown with sucrose compared to succinate as the carbon source (Fig. S2 at doi.org/10.6084/m9.figshare.16556205). While this observation could suggest metabolic regulation of CcrM activity, we instead hypothesize, as displayed in Fig. $2 \mathrm{~A}$, that it is due to DNA replication being initiated later in the cell cycle when E. meliloti is provided sucrose, as recent observations showed that central carbon metabolism influences the rate of DNA polymerase processivity and timing of DNA replication initiation in Bacillus subtilis (44).

Notably, the GANTC methylation pattern differed across replicons within each genome. For example, in E. meliloti Rm2011 the extent of GANTC methylation ranged from 0.80 to 0.98 for pSymB and 0.80 to 0.96 for pSymA, while for the chromosome, the range was from 0.71 to 0.99 (Fig. 1). This result suggests that replication of each replicon is asynchronous, with replication of the secondary replicons being initiated later in the cell cycle than that of the chromosome (model provided as Fig. 2).

A previous study identified 462 cell cycle-regulated genes in E. meliloti Rm1021 (a nearisogenic relative of strain Rm2011 also derived from the nodule isolate SU47) through RNA sequencing of synchronized cell populations (45), which were classified into six groups based on the timing of their expression. We identified 111 cell cycle-regulated genes, belonging to 78 transcripts, that contained at least 1 GANTC in the predicted promoter regions (defined as the 125 bp upstream of the transcript; Data set S1 at doi.org/10.6084/m9.figshare .16556205), and distribution of these 111 genes across the 6 cell cycle gene expression groups was unbiased (45). As these 111 genes are both cell cycle-regulated and contain a GANTC site, they represent an initial candidate CcrM regulon in E. meliloti, although further work is required to identify the CcrM regulon.

Between 31 and 53 GANTC sites were repeatedly not detected as methylated on one or both strands in each of the four wild-type strains (see Data set S2 at doi.org/10.6084/m9 .figshare.16556205), as has also been observed in other species $(17,46)$. However, further work is required to determine if this hypomethylation is biologically meaningful (e.g., CcrM cannot access the site due to binding of another protein [46]) or if it reflects technical artifacts (e.g., low sequencing coverage).

We found it striking that the E. adhaerens OV14 genomes had 2,636 to 2,740 fewer GANTC sites than the other three strains, despite having the largest genome size. Normalized by genome length, there are 1.10 GANTC sites per kb in the $E$. adhaerens OV14 genome (Table 1), which is similar to the 1.12 GANTC sites per kb in C. crescentus NA1000. In contrast, the three legume symbionts contained more than 1.60 GANTC sites per kb across their genomes (Table 1). This result prompted us to examine the frequency and distribution of GANTC sites across 157 Ensifer genomes. As defined previously (47), the genus Ensifer can be broadly subdivided into two monophyletic clades, the "symbiotic" clade (113 strains), in which nearly all strains are legume symbionts, and the "nonsymbiotic" clade (44 strains), in which nearly all strains are nonsymbionts (Fig. 3A). Consistent with previous results (18), GANTC sites occurred less frequently in all genomes (0.90 to 1.83 GANTC sites per $\mathrm{kb}$ ) than expected in a random sequence of nucleotides ( 23.5 GANTC sites per kb). Moreover, GANTC sites were $\sim 2$-fold more common in intergenic regions than in coding regions (Fig. 3B). Strikingly, there was a strong and statistically significant difference ( $P$ value $<1 \times 10^{-10}$; two-sample $t$ test) in the frequency of GANTC sites across the genomes of strains belonging to the symbiotic clade compared to strains of the nonsymbiotic clades (Fig. 3B), with an overall average of 1.70 and 1.06 GANTC sites per $\mathrm{kb}$ in the symbiotic and nonsymbiotic clades, respectively. The difference in the frequency of GANTC sites between the two clades could not be explained by differences in the GC content of these organisms, as both clades had an average GC content of $61.9 \%$ (Fig. S8 at doi.org/10.6084/m9.figshare.16556205), suggesting that the difference reflects underlying differences in the evolution, and possibly the biology, of these two clades.

The impact of bacteroid differentiation on DNA methylation. The only previously published study to examine the role of rhizobium DNA methylation during symbiosis using SMRT sequencing did so in a symbiosis where the bacteria do not undergo terminal differentiation $(38,39)$. To evaluate whether DNA methylation potentially contributes to 

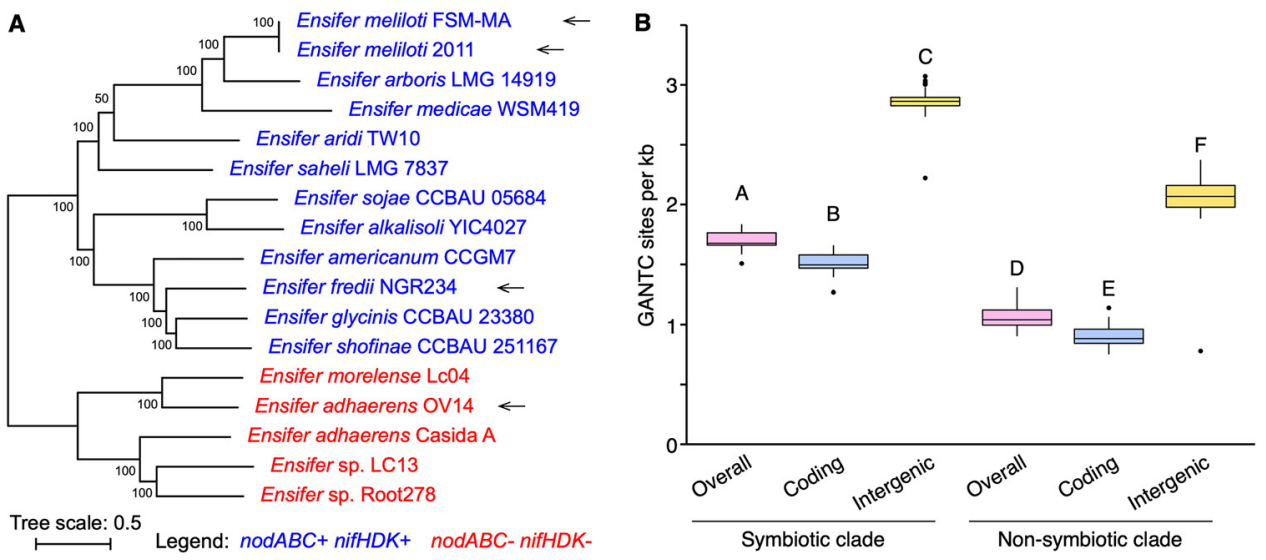

FIG 3 GANTC frequency in the genus Ensifer. (A) An unrooted maximum likelihood phylogeny of 17 representative Ensifer strains. The phylogeny represents the bootstrap best tree following 100 bootstrap replicates, prepared on the basis of the concatenated nucleotide alignments of 1,566 core genes. Values represent the bootstrap support. $\mathrm{N}_{2}$-fixing legume symbionts were identified by the presence of the symbiotic genes nodABC and nifHDK. They are indicated in blue, while red denotes nonsymbiotic strains. The four wild-type strains used in this study are indicated with arrows. (B) Box plots summarizing the frequency of GANTC sites (presented as GANTC sites per kb) in 157 Ensifer strains is shown. The monophyletic "symbiotic" and "non-symbiotic" clades, as defined previously (47), are represented by 113 and 44 genomes, respectively. The densities of GANTC sites across the entire genome (pink), within coding regions (blue), and within intergenic regions (yellow) are shown. Statistically different values $(P<0.05)$ are denoted by uppercase letters as determined by a one-way analysis of variance (ANOVA) followed by Tukey's honestly significant difference (HSD) post hoc test.

regulation of terminal differentiation, we determined the DNA methylation patterns of $E$. meliloti Rm2011 and E. meliloti FSM-MA bacteroids purified from whole Medicago sativa nodules. E. meliloti FSM-MA bacteroids were additionally purified from Medicago truncatula nodules to determine whether the host plant influences bacteroid DNA methylation. $E$. meliloti Rm2011 bacteroids were not isolated from M. truncatula nodules as, unlike FSMMA, Rm2011 forms a poor symbiosis with $M$. truncatula and produces moderately differentiated bacteroids in this host, whereas both strains are equally efficient on M. sativa (48, 49). See Kazmierczak et al. for a detailed description of the symbiotic phenotypes of these two strains of E. meliloti (49).

Moreover, we exploited the spatially distinct developmental zones that are present in indeterminate nodules (50), like those formed by $M$. sativa and $M$. truncatula. At the tip of these nodules, a bacterium-free meristem is present, responsible for the continuous growth of the nodule. Immediately below is the infection and differentiation zone II, where nodule cells become infected and bacteria differentiate into large, polyploid bacteroids. The tip and zone II of nodules appears white. Adjacent to the white zone II is the easily recognizable pinkish zone III (due to the presence of the oxygen-carrying leghemoglobin), where mature bacteroids fix nitrogen. This nodule tissue organization provided an opportunity to examine how DNA methylation patterns may differ between differentiating and differentiated bacteroids. To this end, E. meliloti Rm2011 and FSM-MA bacteroids were isolated from nodules hand-sectioned at the white-pink border; bacteroids isolated from the white sections represent the infecting and differentiating bacteroids (zone II), while those isolated from the pink sections represent the mature, hence terminally differentiated, $\mathrm{N}_{2}$-fixing bacteroids (zone III) (see Fig. S9 at doi.org/10.6084/m9.figshare.16556205 for photographs of the plants).

Fluorescence microscopy and flow cytometry confirmed that nodule sectioning resulted in the isolation of distinct bacteroid populations (Fig. S10 to S13 at doi.org/10 $.6084 / \mathrm{m} 9$. figshare.16556205). Nearly all of the bacteroids isolated from whole-nodule samples and zone III samples were enlarged and polyploid, and most were positive for propidium iodide (PI) staining as expected for terminally differentiated bacteroids (26). In contrast, bacteroids of the zone II samples contained a mix of cell types differing in their size, ploidy level, and PI staining. These data confirmed that the whole-nodule samples and zone III samples consisted predominately of mature $\mathrm{N}_{2}$-fixing bacteroids, 

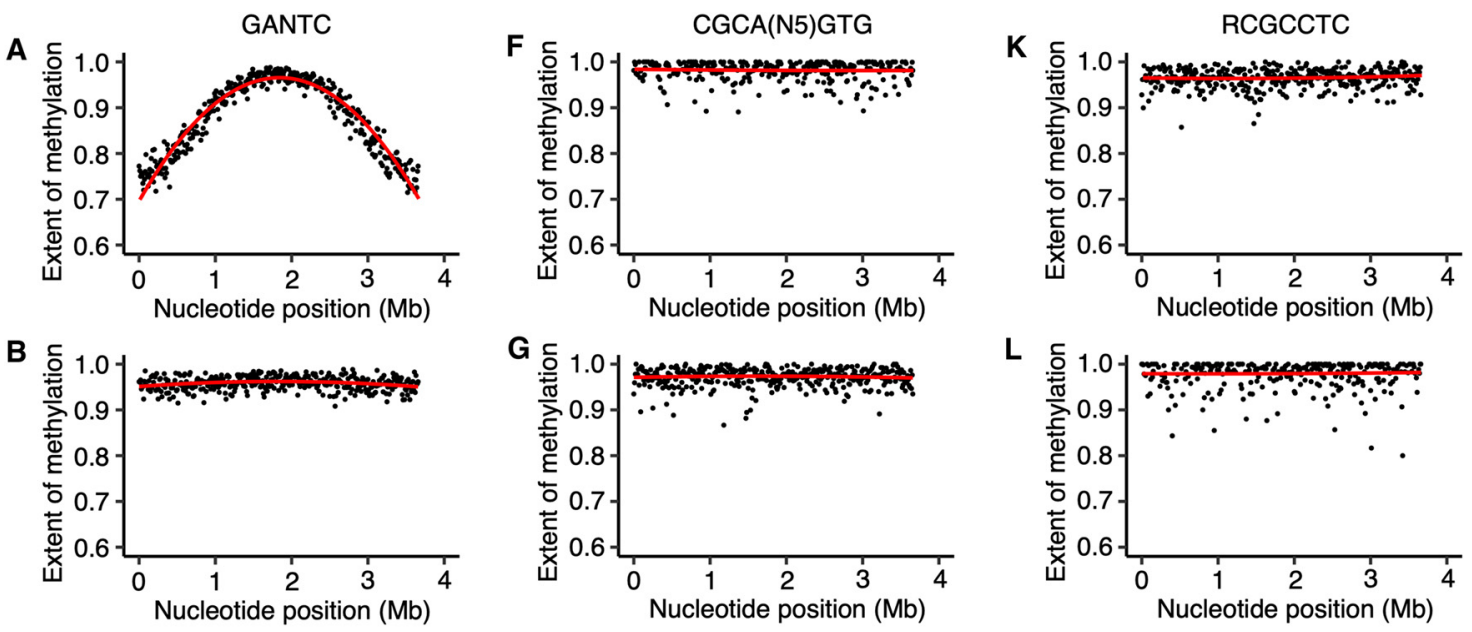

$$
\text { C }
$$
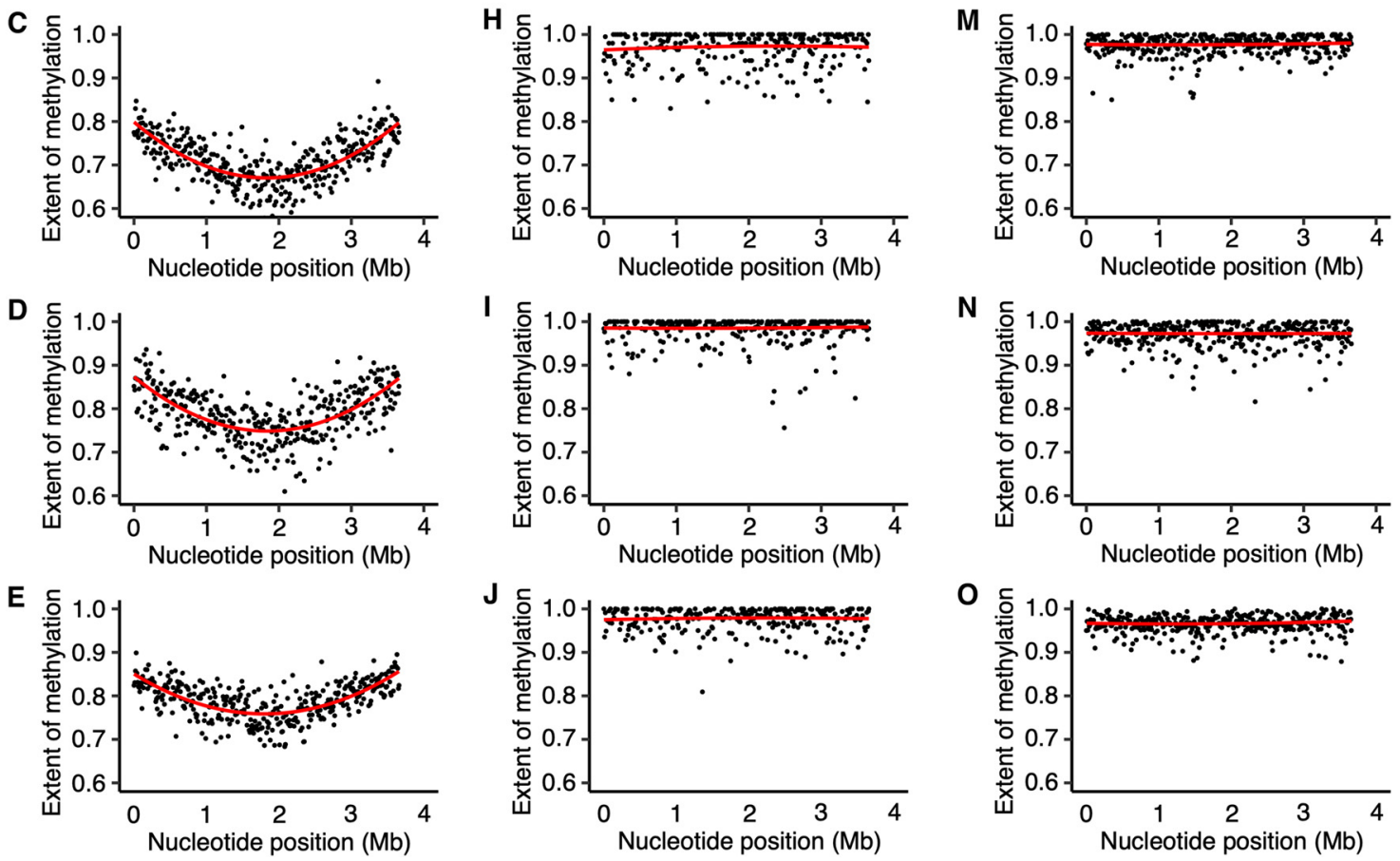

FIG 4 Chromosome-wide DNA methylation of $E$. meliloti Rm2011 bacteroids. (A to O) The extent of methylation of (A to E) GANTC, (F to J) CGCA $\left(\mathrm{N}_{5}\right)$ GTG, and (K to O) RCGCCTC motifs across the E. meliloti Rm2011 chromosome is shown using a 10-kb sliding window. Averages from three biological replicates are shown for free-living and whole-nodule samples; the data represent one replicate for the zone II and zone III nodule sections. (A, F, and K) Free-living cells harvested in mid-exponential phase. (B, G, and L) Free-living cells harvested in early stationary phase. ( $C, H$, and $M$ ) Bacteroids isolated from $M$. sativa zone II nodule sections. ( $D, I$, and $N$ ) Bacteroids isolated from $M$. sativa zone III nodule sections. ( $E$, J, and O) Bacteroids isolated from $M$. sativa whole-nodule samples. The red lines are polynomial regression lines calculated in R using the "rlm" method and the formula "y poly(x,2)." Data for pSymB and pSymA are shown in Fig. S14 and S15 at doi.org/10.6084/m9.figshare.16556205.

whereas the zone II samples contained a mix of cells at various stages of bacteroid differentiation.

With the exception of the GANTC sites (described below), no global difference was observed in the methylation patterns of bacteroids versus free-living cells (Fig. 4 and 5 , and Fig. S14 to S17 at doi.org/10.6084/m9.figshare.16556205). Although a lower percentage of each motif was detected as methylated in the bacteroid samples compared to freeliving samples, this was correlated with lower sequencing depth (Table S2 at doi.org/10 $.6084 / \mathrm{m}$.figshare.16556205) and thus unlikely to be biologically meaningful. Unlike $B$. diazoefficiens USDA110 (38), we did not identify motifs that were methylated specifically in the $E$. meliloti bacteroids. In addition, we found little evidence for any of the methylated motifs being enriched in the promoter regions of $E$. meliloti Rm2011 genes upregulated or 

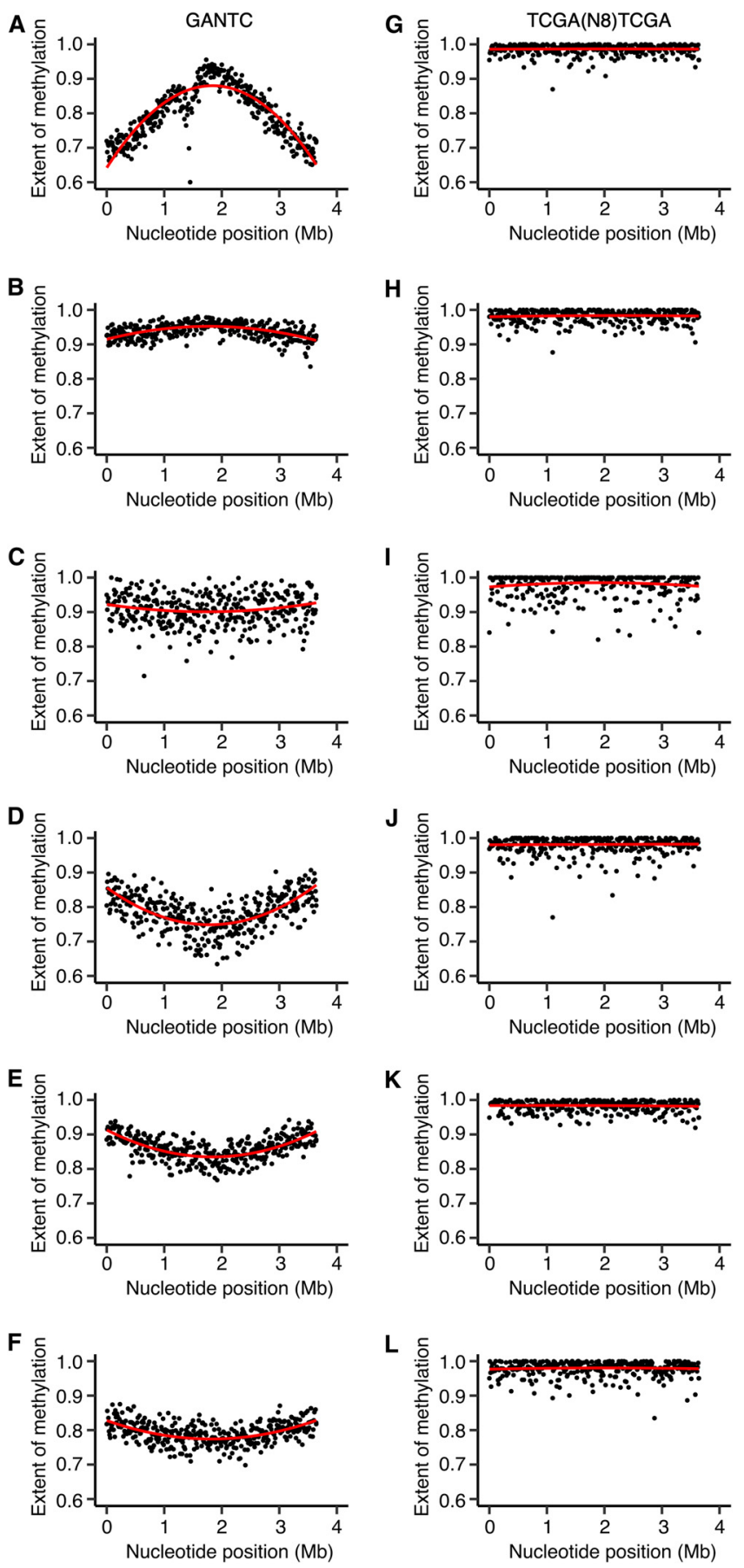

FIG 5 Chromosome-wide DNA methylation of E. meliloti FSM-MA bacteroids. (A to L) The extent of methylation of (A to F) GANTC and ( $G$ to $L$ ) TCGA(N $\left.N_{8}\right)$ TCGA motifs across the E. meliloti FSM-MA chromosome is shown using a 10-kb sliding window. Averages from three biological replicates are shown for free-living and whole-nodule samples; the data represent one replicate for the zone II and zone III nodule sections. (A and G) Free-living cells harvested in mid-exponential phase. ( $B$ and $H$ ) Free-living cells harvested in early stationary phase. ( $C$ and I) Bacteroids isolated from $M$. sativa zone II nodule sections. ( $D$ and J) Bacteroids isolated from $M$. sativa zone III nodule sections. ( $E$ and $\mathrm{K}$ ) Bacteroids isolated from $M$. sativa whole-nodule samples. ( $F$ and $L$ ) Bacteroids isolated from $M$. truncatula whole-nodule samples. The red lines are polynomial regression lines calculated in $\mathrm{R}$ using the "rlm" method and the formula " $\mathrm{y} \sim$ poly $(\mathrm{x}, 2)$." Data for pSymB and pSymA are shown in Fig. S16 and S17 at doi.org/10.6084/m9.figshare.16556205.

downregulated in bacteroids relative to free-living cells, as identified in published transcriptomic data for E. meliloti Rm1021 (23). These data suggest that most DNA methylation is unlikely to be a significant factor in directly regulating gene expression in E. meliloti bacteroids. 
Bacteroid development influences GANTC methylation. Bacteroid development involves cell enlargement and genome endoreduplication, indicative of a cell cycle transition occurring during differentiation (26). Indeed, expression of ccrM and other genes encoding cell cycle regulators vary across stages of bacteroid development and are strongly downregulated in mature nitrogen-fixing E. meliloti bacteroids (24). We were therefore interested in examining whether GANTC methylation by the CcrM MTase was disrupted in bacteroids. Our data revealed a surprising genome-wide pattern of GANTC methylation in E. meliloti Rm2011 and FSM-MA bacteroids, which differed from free-living cells in either the exponential or stationary phases of growth (Fig. 4 and 5 and Fig. S14 to S17 at doi.org/10.6084/m9 .figshare.16556205). The majority of GANTC sites had moderate to high levels of methylation in zone II, zone III, or whole-nodule samples, averaging 0.71 to 0.95 across each replicon (Fig. 4 and 5 and Fig. S14 to S17 and Tables S3 and S4 at doi.org/10.6084/m9.figshare .16556205). Most distinctively, a progressive decrease in the extent of chromosomal methylation of the GANTC sites was observed from ori to ter in nearly all bacteroid samples, revealing a characteristic smiling pattern, which differs from the patterns seen in exponentialphase (frowning pattern, i.e., a progressive increase from ori to ter) and stationary-phase (consistent methylation) cells. The exception was the E. meliloti FSM-MA zone II bacteroid sample, which displayed a consistently high level of GANTC methylation across the genome (Fig. 5C). This pattern, which is different from those in exponential-phase cells as well as mature bacteroids, could correspond to the methylation status of an early stage of bacteroid differentiation. We did not observe the same pattern in the E. meliloti Rm2011 zone II samples. As noted earlier, the zone II samples contain cells at various stages of differentiation (Fig. S10 to S13 at doi.org/10.6084/m9.figshare.16556205). Given that terminal differentiation is associated with an up to 24-fold increase in DNA content, small increases in the proportion of cells at late stages of differentiation could mask the DNA methylation pattern of the cells at early stages of differentiation. Thus, we hypothesize that the Rm2011 zone II sample captures a later stage of differentiation than that captured by the FSM-MA zone II sample. Supporting this hypothesis, the distribution of DNA content per cell in the flow cytometry data was flatter for E. meliloti Rm2011 zone II bacteroids compared to E. meliloti FSM-MA zone II bacteroids (Fig. S18 at doi.org/10.6084/m9.figshare.16556205), which suggests that the former sample represents a broader range of differentiation stages than the latter sample. In contrast to GANTC, the extent of methylation of the second m6A modified motif in each genome was consistently high, irrespective of condition or replicon (Fig. 4 and 5 and Fig. S14 to S17 and Tables S3 and S4 at doi.org/10.6084/m9.figshare.16556205). Similarly, sequencing depth was consistent across the length of each replicon (Fig. S7 at doi.org/10 $.6084 / \mathrm{m} 9$.figshare.16556205). These observations indicate that the changes in GANTC methylation patterns are biologically meaningful and not simply a sequencing artifact.

To further explore changes in CcrM activity during bacteroid differentiation, we took advantage of a collection of $M$. truncatula mutant plant lines ( $d n f 1, d n f 2, d n f 4, d n f 5, d n f 7)$ whose nodules contain bacteria blocked at various stages of differentiation (see Fig. S19 at doi .org/10.6084/m9.figshare.16556205 for photographs of the plants) (51-57). Microscopy and flow cytometry data were consistent with past work (57) showing that bacteroids were blocked at the earliest to latest stages of differentiation in mutant plant lines in the order $d n f 1$ $\rightarrow$ dnf5 $\rightarrow$ dnf $2 \rightarrow$ dnf7 $\rightarrow$ dnf4 (Fig. 6). Nodule bacteria of $M$. truncatula dnf1 mutant plants were small, with one or two haploid genome copies per cell (i.e., ploidy level $=1$ or 2 ) (Fig. $6 \mathrm{~A}$ and $G$ ), suggesting that the cell population was dominated by actively dividing cells that had not yet begun differentiation. Indeed, the GANTC methylation pattern of these cells (Fig. 6M and Fig. S20 and S21 at doi.org/10.6084/m9.figshare.16556205) resembled the frowning pattern of exponentially growing free-living cells (Fig. 5A). Although the nodule bacteria of $M$. truncatula dnf5 mutant plants were also small and undifferentiated into bacteroids, the majority of cells had a ploidy level of 1 (Fig. 6B and H), suggesting these cells had ceased replication but had not yet begun the process of endoreduplication. GANTC methylation was consistently high across the chromosome of bacteria purified from dnf5 nodules (Fig. 6N), similar to stationary-phase free-living cells (Fig. 6B) and indicating that terminal differentiation is preceded by full GANTC methylation. 

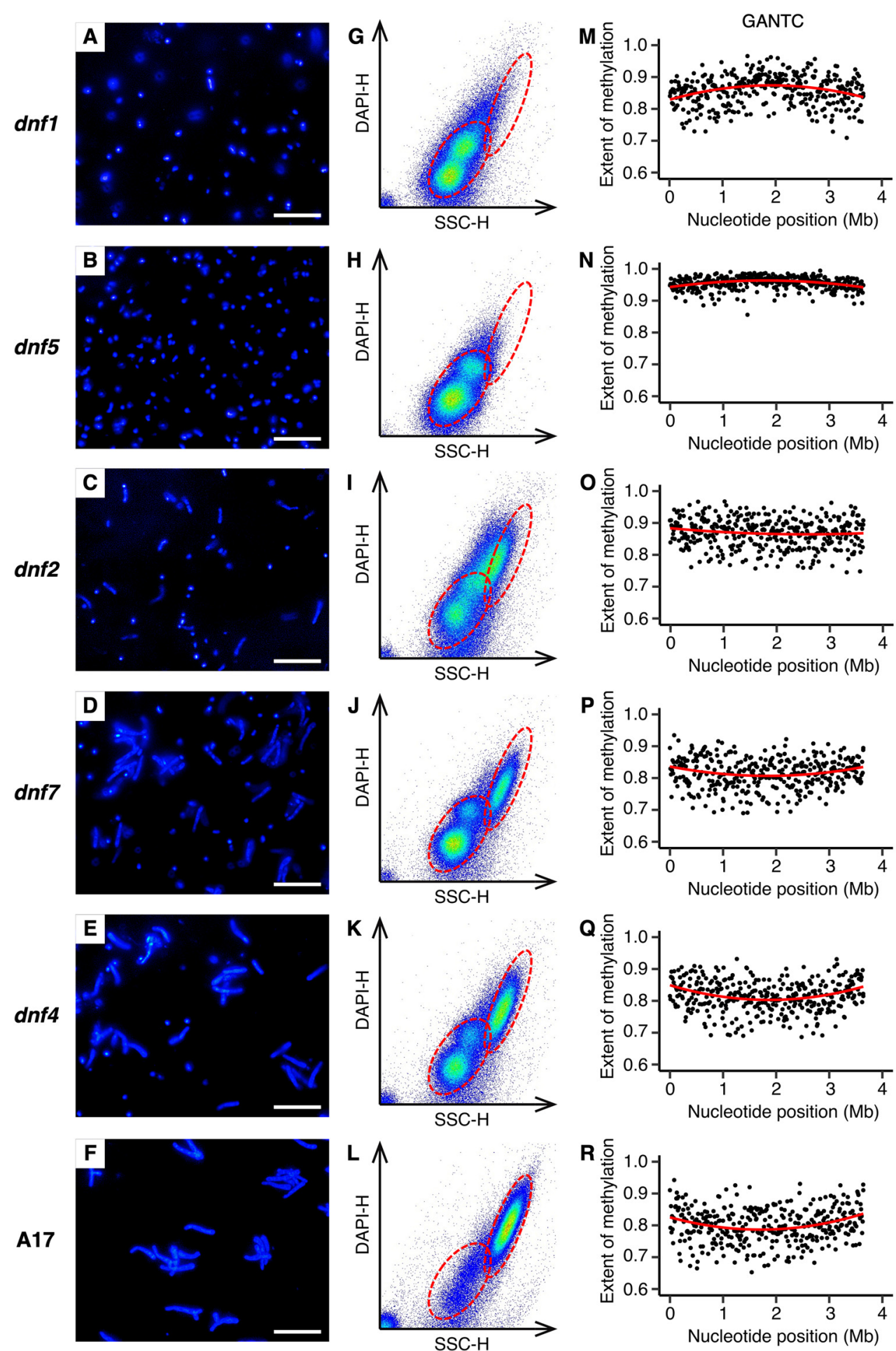
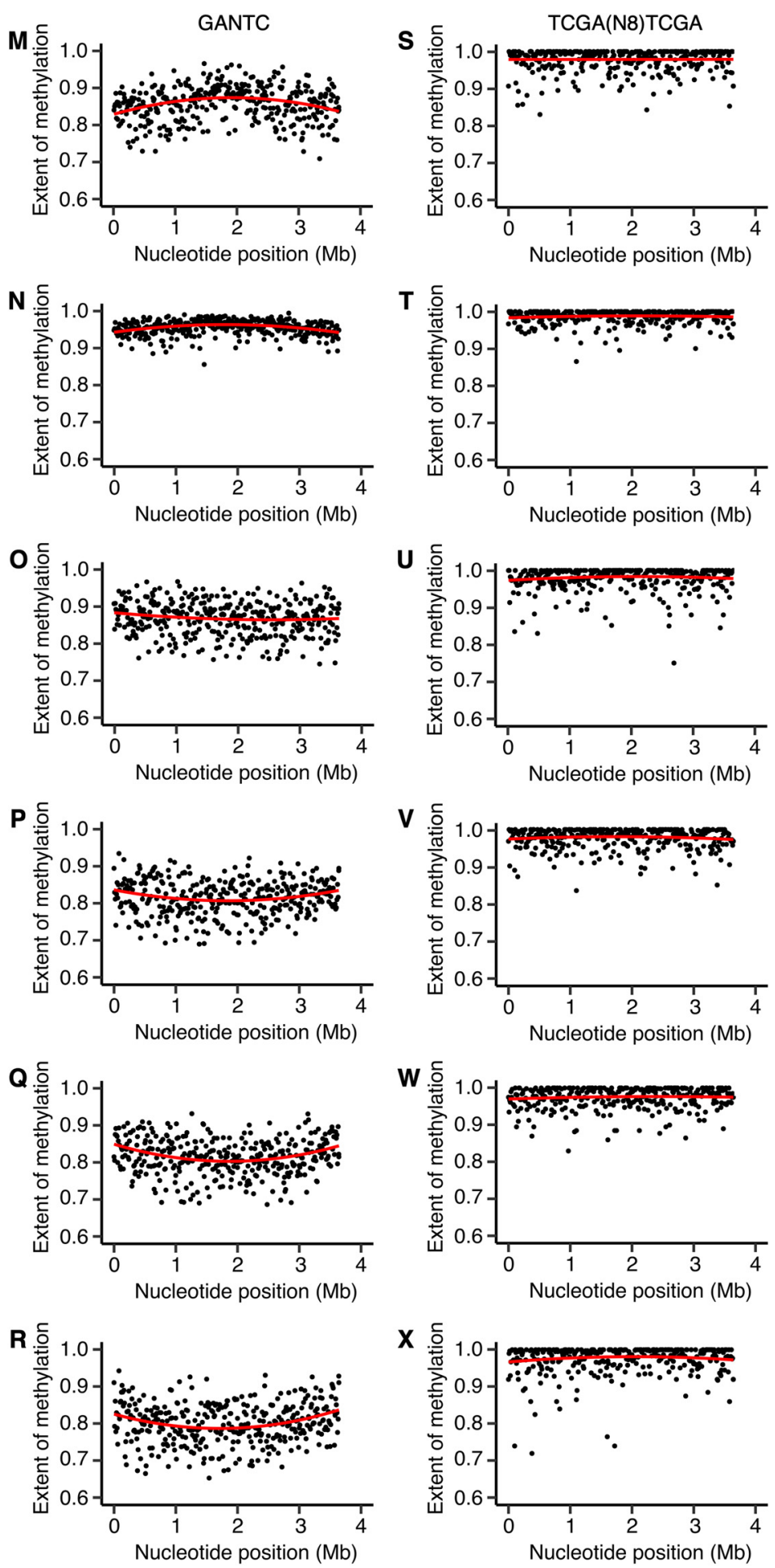

FIG 6 Bacteroid morphology and chromosomal GANTC methylation in E. meliloti bacteroids purified from M. truncatula dnf mutant nodules. (A to X) Data are shown for E. meliloti FSM-MA bacteroids purified from (A, G, M, and S) M. truncatula dnf1 mutant nodules, (B, H, N, and T) M. truncatula dnf5 mutant nodules, (C, I, O, and U) M. truncatula dnf2 mutant nodules, ( $\mathrm{D}, \mathrm{J}, \mathrm{P}, \mathrm{V})$ M. truncatula dnf7 mutant nodules, (E, K, Q, and W) M. truncatula dnf4 mutant nodules, and $(\mathrm{F}, \mathrm{L}, \mathrm{R}$, and $\mathrm{X}) \mathrm{M}$. truncatula A17 wild-type nodules. (A to F) Micrographs of E. meliloti FSM-MA bacteroids stained with the DNA binding dye DAPI. The scale bar represents $30 \mu \mathrm{m}$. (G to L) Pseudocolored scatterplots displaying the cell morphology ( $x$ axis) and DNA content ( $y$ axis) of $E$. meliloti FSM-MA bacteroids, as determined based on flow cytometry analysis of DAPI-stained cells. The red dashed ellipses indicate the position of undifferentiated bacteria as in culture (not shown) or in the dnf1 mutant nodules (lower-left ellipse) or fully mature bacteroids as in the A17 wild-type nodules (top-right ellipse). ( $M$ to $X$ ) The extent of methylation of ( $M$ to R) GANTC or (S to X) TCGA( $\left.\mathrm{N}_{8}\right)$ TCGA motifs across the E. meliloti FSM-MA chromosome, shown using a 10 -kb sliding window. The red lines are polynomial regression lines calculated in $\mathrm{R}$ using the "rlm" method and the formula " $\mathrm{r} \sim \mathrm{poly}(\mathrm{x}, 2)$. " Data for pSymB and pSymA are shown in Fig. S20 and S21 at doi.org/10.6084/m9.figshare.16556205. 
TABLE 2 Relative sequencing depth of each E. meliloti replicon

\begin{tabular}{lllll}
\hline & & \multicolumn{3}{l}{ Relative mean sequencing depth $^{a}$} \\
\cline { 3 - 5 } Strain & Condition & Chromosome & pSymA & pSymB \\
\hline Rm2011 & Mid-exponential phase & $1.00 \pm 0.00$ & $1.00 \pm 0.03$ & $0.98 \pm 0.03$ \\
Rm2011 & Stationary phase & $1.00 \pm 0.00$ & $1.06 \pm 0.02$ & $1.02 \pm 0.03$ \\
Rm2011 & M. sativa bacteroids & $1.00 \pm 0.00$ & $0.64 \pm 0.02$ & $0.62 \pm 0.02$ \\
FSM-MA & Mid-exponential phase & $1.00 \pm 0.00$ & $1.02 \pm 0.03$ & $0.87 \pm 0.05$ \\
FSM-MA & Stationary phase & $1.00 \pm 0.00$ & $1.10 \pm 0.00$ & $1.01 \pm 0.03$ \\
FSM-MA & M. sativa bacteroids & $1.00 \pm 0.00$ & $0.79 \pm 0.04$ & $0.71 \pm 0.02$ \\
FSM-MA & M. truncatula bacteroids & $1.00 \pm 0.00$ & $0.66 \pm 0.02$ & $0.59 \pm 0.01$ \\
FSM-MA & dnf1 bacterial cells & 1.00 & 0.98 & 0.90 \\
FSM-MA & dnf5 bacterial dells & 1.00 & 0.96 & 0.94 \\
FSM-MA & dnf2 bacterial dells & 1.00 & 0.81 & 0.73 \\
FSM-MA & dnf7 bacterial dells & 1.00 & 0.82 & 0.71 \\
FSM-MA & dnf4 bacterial dells & 1.00 & 0.80 & 0.73 \\
FSM-MA & A17 bacteroids & 1.00 & 0.76 & 0.67 \\
\hline
\end{tabular}

aSequencing depth is presented relative to the sequencing depth of the chromosome in the same sample.

Values are the means of triplicate samples \pm standard deviation, except for the lower half of the table, for which numbers are based on a single replicate.

The nodule bacteria purified from M. truncatula dnf2 mutant nodules were a mix of undifferentiated and partially differentiated bacteroids, which were polyploid to an extent similar to bacteroids purified from wild-type A17 nodules (Fig. $6 \mathrm{l}$ compared to Fig. 6L); however, their cell size was much smaller (Fig. 6C compared to Fig. 6F). This was similar to differentiating bacteroids purified from $M$. truncatula and M. sativa zone II nodule sections, many of which had high ploidy without a corresponding increase in cell size (Fig. S11 and S13 at doi.org/10.6084/m9.figshare.16556205). The GANTC methylation pattern of bacteroids from dnf2 nodules (Fig. 60) was also similar to that of zone II nodule sections. There was a consistently high extent of GANTC methylation across the chromosome averaging 0.870 , which was less than that of bacteroids purified from dnf5 nodules (0.956) but higher than that of bacteroids purified from wildtype A17 nodules (0.804) (Table S5 at doi.org/10.6084/m9.figshare.16556205), and without the smiling pattern. The nodule bacteria purified from $M$. truncatula dnf7 and dnf4 nodules also contained a mix of undifferentiated bacteria and fully differentiated bacteroids (Fig. 6D, E, J, and K), with the number of undifferentiated bacteria greater in $d n f 7$ nodules compared to $d n f 4$ nodules. The GANTC methylation pattern of bacteroids purified from $d n f 7$ and $d n f 4$ nodules was similar to that of bacteroids purified from A17 nodules (Fig. 6P and Q). Overall, we interpret the data from bacteroids purified from section nodules and $M$. truncatula dnf mutant nodules as suggesting that CcrM is dysregulated during terminal bacteroid differentiation and that CcrM is constitutively active during endoreduplication.

Chromosome, pSymB, and pSymA sequencing depth are unequal in $E$. meliloti bacteroids. We noticed that in each bacteroid sample, the average extent of GANTC methylation for the chromosomes of the two strains was lower (by 0.04 to 0.13 ) than that of pSymA or pSymB, and unlike the chromosome, the extent of GANTC methylation was relatively constant across pSymA and pSymB (Fig. S14 to S17 compared to Fig. 4 and 5). These results suggest that, unlike in free-living cells, replication of the three replicons is not well coordinated during terminal differentiation. In agreement with this hypothesis, the mean sequencing depth across pSymA and pSymB was on average $\sim 33 \%$ lower than that of the chromosome in all replicates of the E. meliloti whole-nodule bacteroid samples (Table 2). Similarly, the mean sequencing depth across pSymA and pSymB was on average $\sim 23 \%$ lower than that of the chromosome for the polyploid bacterial cell populations purified from M. truncatula dnf2, dnf7, and dnf4 mutant nodules, but not for the haploid/ diploid bacterial cell populations purified from M. truncatula dnf1 and dnf5 mutant nodules (Table 2). Assuming sequencing depth is correlated with copy number, this observation suggests that $E$. meliloti bacteroids carry approximately two copies each of pSymA and pSymB per three copies of the chromosome. 


\section{DISCUSSION}

In this study, we examined the genome-wide DNA methylation patterns in the free-living cells of four Ensifer strains, and in bacteroids of two E. meliloti strains, and detected a total of six methylated motifs. We were able to predict cognate MTases for most of the motifs based on genome annotations, the exception being the WNCCGATG motif of E. adhaerens OV14. The CGCA $\left(\mathrm{N}_{5}\right)$ GTG motif of E. meliloti Rm2011 is presumably methylated by Smc02296 (HsdM), a predicted m6A MTase belonging to the HsdRSM type I R-M system that is known to be functional and reduce transformation efficiency $(58,59)$. The RCGCCTC motif of E. meliloti Rm2011 is possibly methylated by Smc03763, a predicted cytosine MTase located upstream of the gene vsr, which putatively encodes a very short patch repair protein. However, as MTases encoded upstream of vsr-like genes generally create m5C modifications-not m4C modification as in the RCGCCTC motif-it is possible that methylation of RCGCCTC may instead occur by an unidentified MTase (60). Neither of these proteins are found in the other three strains examined here. The motifs TCGA $\left(\mathrm{N}_{8}\right)$ TCGA of E. meliloti FSM-MA and CAGA $\left(\mathrm{N}_{7}\right) \mathrm{GTTG}$ of $E$. fredii NGR234 are likely methylated by SMB554_16155 and NGR_c01340, respectively, which are $88 \%$ identical at the amino acid level and appear to function as part of R-M systems. Homologs of these two proteins are not found in the other two strains.

Except for GANTC, each methylated motif was detected as methylated only in a single strain. Moreover, MTases, apart from CcrM, are not conserved among E. meliloti strains. The lack of conservation suggests that most DNA MTases do not have a major regulatory role in the genus Ensifer, aside from CcrM and its role in cell cycle regulation. Supporting this conclusion, no motif was enriched in the promoter regions of symbiosis, carbon source, or cell cycle-regulated genes, and we did not detect any motifs that were methylated specifically in bacteroids. However, we cannot rule out that one or more methylated motifs may influence specific gene expression during free-living growth, differentiation, or $\mathrm{N}_{2}$-fixation through extended motifs or proximity to other promoter elements, similar to the interplay between CcrM and GcrA during cell cycle regulation in C. crescentus $(20,46)$.

As previously published studies have provided evidence for a cell cycle transition occurring during terminal bacteroid differentiation (26), we were particularly interested in CcrM, a cell cycle-regulated MTase that is broadly conserved in the Alphaproteobacteria, and its cognate DNA motif, GANTC. By identifying GANTC sites in the promoter regions of a previously determined set of 462 cell cycle-regulated genes (45), we defined a candidate CcrM regulon in $E$. meliloti consisting of 111 genes. However, further studies are required to better delineate the CcrM regulon in E. meliloti, as individual GANTC sites are not diagnostic of a specific gene being regulated by CcrM; GANTC sites were found in the promoter regions of 904 transcripts that did not display cell cycle regulation, and the promoter regions of cell cycle-regulated genes were not enriched in GANTC sites relative to the whole E. meliloti genome. Studies in C. crescentus suggest that the impact of the fully or hemi-methylated status of GANTC sites on gene expression is mediated, at least in part, through modulating the activity of the transcriptional regulator $\operatorname{GcrA}(20,61)$. However, not all promoter sites containing a GANTC motif are regulated by GcrA in C. crescentus, with the relationship dependent on an extended YGAKTCK motif and the precise position of this motif relative to other promoter elements (61). Likely, CcrM-mediated gene regulation in the genus Ensifer is also dependent upon additional sequence elements beyond the GANTC motif. Nevertheless, as a recent study in the alphaproteobacterium Brevundimonas subvibrioides suggested (46), the CcrM and GcrA regulons as well as the GcrA-binding motif can show very little overlap between species, and therefore they will have to be defined experimentally in E. meliloti.

Consistent with past observations (18), GANTC sites were underrepresented in the genomes of 157 Ensifer strains, particularly within coding regions. More surprising, however, was the strong difference in the frequency of GANTC sites between the previously defined (47) symbiotic and nonsymbiotic clades in the genus Ensifer, with the frequency of GANTC sites being $\sim 60 \%$ higher in the symbiotic clade. Although further work is required to understand the biological significance of the greater frequency of GANTC sites in the symbiotic clade, it is tempting to speculate that it is associated with legume symbiosis. 
Our data are consistent with CcrM activity differing during terminal bacteroid differentiation compared to free-living cells. The overall moderate to high rates of GANTC methylation in all E. meliloti bacteroid samples, coupled with the lack of a chromosome-wide pattern in the E. meliloti FSM-MA zone II sample, leads us to hypothesize that CcrM remains constitutively active throughout most of terminal differentiation. This hypothesis is supported by the results for nodule bacteria purified from M. truncatula dnf mutant nodules, which showed that differentiation is preceded by full GANTC methylation and that GANTC methylation remains high (but moderately lower) during endoreduplication, followed by another moderate drop in GANTC methylation in late stages of differentiation. Considering that overexpression of CcrM can give rise to bacteroid-like morphology in free-living cells (14), we hypothesize that constitutive CcrM MTase activity is one (of potentially multiple) factor(s) driving polyploidization of bacteroids (Fig. 2). However, further studies monitoring CcrM abundance and artificially manipulating ccrM expression throughout bacteroid differentiation are required to conclusively determine if $\mathrm{CcrM}$ is constitutively active during terminal differentiation and the importance of this activity to the promotion of endoreduplication.

CcrM activity is confined to a short window in the cell cycle since the ccrM gene is expressed in the late phase of genome replication (45) and, at least in C. crescentus, the CcrM protein is degraded by the Lon protease prior to cell division (62). Thus, constitutive CcrM MTase activity in differentiating bacteroids could be obtained through an aberrant expression of the gene or, alternatively, a lack of proteolytic degradation of the CcrM protein. In agreement with the latter possibility, Lon protease was identified as a target of the NCR247 peptide (34). NCR247 is one of the $\sim 600$ NCR peptides produced by M. truncatula that induce bacteroid terminal differentiation, and studies suggest that NCR247 does so at least in part by perturbing expression of genes involved in cell cycle regulation (33). It is tempting to speculate that NCR peptides such as NCR247 inhibit Lon protease activity posttranslationally, thereby stabilizing CcrM and triggering bacteroid differentiation. However, the CcrM MTase does not appear to remain active in fully differentiated bacteroids, with the lower GANTC methylation near the chromosomal ter regions suggesting that loss of CcrM MTase activity occurs slightly prior to completion of genome endoreduplication (model provided as Fig. 2). These hypotheses are consistent with $M$. truncatula-E. meliloti nodule zone-specific RNA-sequencing data (24), which showed that ccrM expression in the root distal portion of zone II is $\sim 2$-fold higher than in the root proximal portion of zone II and $\sim 10$-fold higher than in zone III. The $\sim 10$-fold difference in ccrM expression across nodule zones suggests to us that the level of ccrM expression during early stages of bacteroid differentiation is biologically significant, a prerequisite for the constitutive CcrM activity that we hypothesize.

Our analyses also provide insight into the genome replication dynamics of $E$. meliloti during free-living growth and terminal bacteroid differentiation. Notably, flow cytometry data of $E$. meliloti bacteroids purified from zone II nodule sections and M. truncatula dnf2 nodules suggest that endoreduplication and cell enlargement largely occur subsequently, not concurrently. Genome replication might be a much faster process than cell growth or, alternatively, endoreduplication might be required to drive cell enlargement. Moreover, our data are consistent with a loss of coordination of replication of the three replicons during terminal bacteroid differentiation, leading to unequal copy numbers, with two copies of pSymA and pSymB per three copies of the chromosome in bacteroids. This differs from free-living cells, where the copy number of the three replicons was approximately equal based on average sequencing depth. We hypothesize that this is a consequence of pSymA and pSymB encoding their own replication proteins and having independent regulation of replication initiation and copy number from that of the chromosome $(63,64)$. The relative change in replicon copy number occurs concomitantly with differentiation and polyploidization, as supported by the relative abundance of the replicons differing in nodule bacterial cells that have experienced endoreduplication (i.e., cells retrieved from $M$. truncatula $d n f 2, d n f 7$, and dnf4 mutant nodules) but not in bacterial cells that had not yet undergone endoreduplication (i.e., cells retrieved from $M$. truncatula $d n f 1$ and $d n f 5$ mutant nodules). In contrast to our results, a previous comparison of the relative abundance of the three replicons in free-living 
E. meliloti Rm1021 versus bacteroids did not detect differences using comparative genome hybridization with microarrays (26). We believe that the difference between our present data and the previous analysis is due to the subtlety of the differences and the lower sensitivity of the microarray hybridization method compared to high-throughput sequencing.

We also observed that during free-living exponential growth, the extent of GANTC methylation at the ori of pSymA and pSymB is higher than at the ori of the chromosome, while the ter of the pSymA and pSymB has a slightly lower extent of GANTC methylation than the ter of the chromosome. As GANTC methylation occurs at a fixed stage of the cell cycle corresponding to the end of chromosome replication, our observations indicate that $\mathrm{pSymA}$ and $\mathrm{pSymB}$ replication is initiated later in the cell cycle than initiation of chromosome replication, while their replication terminates slightly before completion of chromosomal replication and the activation of CcrM (model provided as Fig. 2). These results provide additional support for the notion of spatiotemporal regulation of DNA replication and partitioning in the multipartite $E$. meliloti genome as proposed previously $(45,65)$. Similarly, replication of chromosome II of Vibrio cholerae is delayed relative to chromosome I, leading to the replication of these two replicons terminating at approximately the same time (66). Thus, coordinating the timing or replication termination may be a general feature of multipartite genomes.

\section{MATERIALS AND METHODS}

Experimental design. The overall experimental design is summarized in Fig. S1 at doi.org/10.6084/ m9.figshare.16556205. Genomic DNA was isolated from four wild-type Ensifer strains to explore how DNA methylation varies across this genus; to allow direct comparison, the four strains were grown to mid-exponential phase in minimal medium with succinate as a carbon source. To investigate how DNA methylation patterns differ between actively dividing and nondividing cells, genomic DNA was isolated from E. meliloti Rm2011 grown to either mid-exponential phase or stationary phase. Genomic DNA was isolated from E. meliloti Rm2011 grown to mid-exponential phase with either a glycolytic (sucrose) or gluconeogenic (succinate) carbon source to investigate whether DNA methylation may play a role in regulating carbon metabolism. Furthermore, an E. meliloti Rm2011 derivative lacking the pSymA and pSymB replicons (named RmP3496) was studied to gain insight into whether these replicons contribute to DNA methylation patterns in E. meliloti Rm2011; this strain was grown with sucrose (instead of succinate), as RmP3496 lacks the succinate transporter.

In addition to the free-living samples, E. meliloti bacteroid samples purified from legume nodules were collected to investigate changes in DNA methylation during bacteroid differentiation and nitrogen fixation. To do so, E. meliloti Rm2011 and E. meliloti FSM-MA bacteroids were isolated from M. sativa whole nodules. E. meliloti FSM-MA bacteroids were additionally purified from M. truncatula whole nodules to examine the impact of the host plant on bacteroid DNA methylation patterns. E. meliloti Rm2011 bacteroids were only isolated from M. sativa nodules, as unlike FSM-MA, Rm2011 forms a poor symbiosis with M. truncatula $(48,49)$. Moreover, E. meliloti Rm2011 and E. meliloti FSM-MA bacteroids were isolated from $M$. sativa nodule sections (sectioned at the white-pink border to separate the root distal infection and differentiation zone II [white] from the root proximal nitrogen-fixing zone III [pink]) to facilitate an analysis of how DNA methylation patterns differ between differentiating bacteroids and fully differentiated and nitrogen-fixing bacteroids. This was followed by isolation of $E$. meliloti FSM-MA bacteroids from whole nodules of $M$. truncatula mutant lines ( $d n f 1, d n f 2, d n f 4, d n f 5, d n f 7$ ) to investigate DNA methylation patterns in nodule bacteria blocked as various stages of differentiation.

Bacterial strains and growth conditions. The bacterial strains used in this work are listed in Table S6 at doi.org/10.6084/m9.figshare.16556205. All strains were routinely grown on tryptone-yeast (TY) with $2 \mu \mathrm{M} \mathrm{CoCl}_{2}$, as it was required for E. meliloti RmP3496 (42). The MM9 minimal medium (42) consisted of the following: $40 \mathrm{mM}$ MOPS (morpholinepropanesulfonic acid), $20 \mathrm{mM} \mathrm{KOH}, 19.2 \mathrm{mM} \mathrm{NH}_{4} \mathrm{Cl}, 85.6 \mathrm{mM} \mathrm{NaCl}$, $2 \mathrm{mM} \mathrm{KH}_{2} \mathrm{PO}_{4}, 1 \mathrm{mM} \mathrm{MgSO}_{4}, 0.25 \mathrm{mM} \mathrm{CaCl}_{2}, 1 \mu \mathrm{g} \mathrm{mL}^{-1}$ biotin, $42 \mathrm{nM} \mathrm{CoCl}, 38 \mu \mathrm{M} \mathrm{FeCl}_{3}, 10 \mu \mathrm{M}$ thiamine$\mathrm{HCl}$, and either $10 \mathrm{mM}$ sucrose (MM9-sucrose) or $20 \mathrm{mM}$ disodium succinate (MM9-succinate). Prior to inoculation of plants with E. meliloti, the strains were grown in yeast extract-beef broth (YEB) medium (67).

DNA isolation from free-living cells. Overnight cultures of all strains grown in MM9-succinate or MM9-sucrose medium were diluted into $10 \mathrm{~mL}$ of the same medium to a starting optical density at 600 $\mathrm{nm}\left(\mathrm{OD}_{600 \mathrm{~nm}}\right)$ of 0.025 ( 0.05 for $\left.\mathrm{RmP3496}\right)$ and incubated overnight at $30^{\circ} \mathrm{C}$ with shaking (130 rpm). The next day, cultures were diluted into $40 \mathrm{~mL}$ of the same medium in $100-\mathrm{mL}$ flasks to the $\mathrm{OD}_{600 \mathrm{~nm}}$ values listed in Table S7 at doi.org/10.6084/m9.figshare.16556205. To obtain mid-exponential-phase samples, cultures were harvested after 15.5 to $16 \mathrm{~h}$ of growth at $\mathrm{OD}_{600 \mathrm{~nm}}$ values between 0.37 and 0.69 (Table S7 at doi.org/10.6084/ m9.figshare.16556205). To obtain stationary-phase samples, cultures were harvested after $24 \mathrm{~h}$ of growth at $\mathrm{OD}_{600 \mathrm{~nm}}$ values of $\sim 1.4$. In all cases, cultures were streaked on TY plates to check for contamination and then centrifuged $\left(8,200 \times \mathrm{g}, 10 \mathrm{~min}, 4^{\circ} \mathrm{C}\right)$; the full $40 \mathrm{~mL}$ was centrifuged for mid-exponential-phase cultures, whereas only $15 \mathrm{~mL}$ was centrifuged for stationary-phase cultures. Most of the supernatant was discarded, and the pellet was resuspended in the remaining volume, transferred to a $2-\mathrm{mL}$ tube and centrifuged again $(16,200 \times g$, room temperature, $1 \mathrm{~min})$, and the supernatant was discarded. Three biological replicates, each starting from a separate overnight culture, were performed. DNA was isolated using phenol:chloroform extractions 
and ammonium acetate precipitations as described elsewhere (68), and the DNA pellets (following RNase A treatment) were resuspended in $200 \mu \mathrm{L}$ of $10 \mathrm{mM}$ Tris- $\mathrm{HCl}$, pH 8.5 .

DNA isolation from bacteroids. $M$. sativa cv. Gabès and $M$. truncatula cv. A17 were the wild-type plants used for all experiments. M. truncatula dnf1, dnf2, dnf4, dnf5, and dnf7 mutants (51), derived from the A17 wild type, were used for collection of bacteroids blocked at various stages of differentiation. Seeds were scarified, surface sterilized, and germinated on Kalys agar as described previously (49). First, $50 \mathrm{~mL}$ of overnight cultures of E. meliloti Rm2011 or FSM-MA, grown in YEB, were centrifuged $(4,000 \times g, 20$ min, room temperature) and resuspended in $\sim 1,200 \mathrm{~mL}$ of sterile, distilled water to obtain a cell suspension at an $\mathrm{OD}_{600 \mathrm{~nm}}$ of $\sim 0.1$. Germinated seedlings were immersed for $1 \mathrm{~h}$ in the appropriate rhizobial cell suspension and then planted in a perlite:sand (2:1) mixture. Plants were grown in a greenhouse for five to six weeks, with occasional watering with a $1 \mathrm{~g} \mathrm{~L}^{-1}$ nutrient solution (PlantProd solution [N-P-K, 0-15-40]).

For whole-nodule samples of wild-type plants, pink nodules were collected from 53 to 60 plants per replicate 34- to 35-day postinoculation; in the case of dnf mutants (and a matched wild-type A17 sample), nodules were collected from $\sim 105$ plants per genotype 23 to 24 days postinoculation. Nodules were collected from the roots and stored in tubes in liquid nitrogen until collection was complete, at which point they were stored at $-80^{\circ} \mathrm{C}$ until use. For sectioned nodule samples, pink nodules were collected from 103 M. sativa plants for each of the microsymbionts 35 to 40 days postinoculation. Nodules were manually sectioned at the white-pink border. Nodule sections were stored in tubes over dry ice or liquid nitrogen until collection was complete, at which point they were stored at $-80^{\circ} \mathrm{C}$ until use. Average plant shoot dry weights for all samples are listed in Table S8 at doi.org/10.6084/m9.figshare .16556205. Bacteroids were isolated from the nodule samples using Percoll gradient centrifugation as described elsewhere (26). The recovered bacteroids were resuspended in 50 to $100 \mu \mathrm{L}$ of bacteroid extraction buffer (BEB; $125 \mathrm{mM} \mathrm{KCl}, 50 \mathrm{mM}$ Na-succinate, $50 \mathrm{mM}$ TES [ $N$-tris(hydroxymethyl)methyl-2aminoethanesulfonic acid], $\mathrm{pH}$ 7.0) and either used immediately for microscopy, flow cytometry, and DNA isolation or stored at $-80^{\circ} \mathrm{C}$ until use.

Nucleic acids were initially purified from most bacteroid samples using the Epicentre MasterPure complete DNA and RNA purification kit, following the protocol for DNA isolation from cell samples; the exceptions were bacteroids purified from dnf mutant nodules (and the matched wild-type A17 sample), for which nucleic acids were isolated by using phenol:chloroform extractions followed by ammonium acetate DNA precipitations as described elsewhere (68). For sectioned-nodule samples, pure DNA was isolated by using the manufacturer's protocol for the complete removal of RNA. For whole-nodule samples, the isolated DNA was further purified by treating the nucleic acid samples with RNase A, after which pure DNA was isolated by using phenol:chloroform extractions followed by ammonium acetate DNA precipitations or, alternatively, using the MasterPure DNA cleanup protocol for the DNA from $d n f$ mutant nodules and the matched wild-type A17 sample. In all cases, the final DNA pellets were resuspended in $200 \mu \mathrm{L}$ of $10 \mathrm{mM}$ Tris- $\mathrm{HCl}, \mathrm{pH}$ 8.5. Three biological replicates were performed for bacteroids isolated from most whole nodules, whereas only one replicate was performed for bacteroids isolated from sectioned nodules or dnf mutant nodules (and the matched wild-type A17 sample) due to low quantities of starting materials.

DNA sequencing, modification detection, and motif analysis. DNA sequencing was performed at the U.S. Department of Energy Joint Genome Institute (JGI) or in-house at the University of Florence (the stationary-phase samples and dnf mutant nodules and the matched wild-type A17 sample) using Pacific Biosciences (PacBio) sequencing technology (69). Genomic DNA was sheared to $3 \mathrm{~kb}$ using an LS220 (Covaris, Inc., Woburn, MA, USA) or $15 \mathrm{~kb}$ (for stationary-phase samples and bacteroids isolated from dnf mutant nodules and the matched wild-type A17 sample) using g-TUBEs (Covaris, Inc.). Sheared DNA was treated with exonuclease to remove single-stranded ends and DNA damage repair mix followed by end repair and ligation of barcoded blunt adapters using the SMRTbell template prep kit 2.0 (PacBio, Menlo Park, CA, USA). Libraries were purified with AMPure PB beads (Beckman Coulter, Brea, CA, USA), and three or eight libraries with different barcodes were pooled at equimolar ratios and purified with AMPure PB beads. For most samples, SMRTbell template libraries were prepared using a Sequel binding kit 3.0 (PacBio, Menlo Park, (A, USA) and sequenced on a Sequel instrument using a v3 or v4 sequencing primer, $1 \mathrm{M}$ v3 SMRT cells, and version 3.0 sequencing chemistry with $1 \times 360$ or $1 \times 600$ sequencing movie run times. The exceptions were the E. meliloti Rm2011 zone II and E. meliloti FSM-MA zone III bacteroid samples. For these samples, SMRTbell template libraries were prepared using a Sequel II binding kit 2.0 (PacBio) and then sequenced on a Sequel II instrument using the tbd-sample-dependent sequencing primer, $8 \mathrm{M}$ v1 SMRT cells, and version 2.0 sequencing chemistry with $1 \times 900$ sequencing movie run times.

DNA modification detection and motif analysis were performed using the SMRT Link software (PacBio, Menlo Park, CA, USA). Briefly, raw reads were filtered using SFilter to remove short reads and reads derived from sequencing adapters. Filtered reads were aligned against the appropriate reference genome (Table S2 at doi.org/10.6084/m9.figshare.16556205) using BLASR (70), and modified sites were then identified through kinetic analysis of the aligned DNA sequence data (71); the number of mapped bases per sample is provided in Table S2 at doi.org/10.6084/m9.figshare.16556205. Modified sites were then grouped into motifs using MotifFinder. These motifs represent the recognition sequences of MTase genes active in the genome (72). Downstream analyses were performed using custom Perl and R scripts.

Flow cytometry. Flow cytometry was performed as described previously (26). Freshly prepared bacteroid samples were diluted in $200 \mu \mathrm{L}$ of $\mathrm{BEB}$, heat-treated for $10 \mathrm{~min}$ in a $70^{\circ} \mathrm{C}$ water bath, and then stained with the DNA-binding dye diamidino-2-phenylindole (DAPI). Cell size and ploidy level of the bacteroid samples were determined using flow cytometry with a Beckman Coulter CytoFLEX S instrument. Measurements consisted of 50,000 cells. Data analysis was performed using the CytExpert 2.2.0.97 software. 
Fluorescence microscopy. One $\mu \mathrm{L}$ of each freshly prepared bacteroid sample was mixed with $1 \mu \mathrm{L}$ of $50 \mu \mathrm{g} \mathrm{mL}^{-1}$ DAPI or with both $1 \mu \mathrm{L}$ of $50 \mu \mathrm{g} \mathrm{mL}^{-1}$ DAPI and $1 \mu \mathrm{L}$ of $100 \mu \mathrm{g} \mathrm{mL}^{-1}$ propidium iodide (PI), which are both DNA binding dyes. Samples were visualized at $\times 100$ magnification under oil immersion using a Nikon Eclipse 80i fluorescence microscope with the NIS-Elements BR 4.00.01 software and a Digital Sight DS-U3 camera.

Phylogenetic analysis. The nucleotide fasta files of representative Ensifer species were downloaded from the National Centre for Biotechnology Information (NCBI) genome database. A core gene phylogeny was constructed using a previously prepared pipeline (73) reliant on the use of Roary 3.11.3 (74), Prokka 1.12-beta (75), PRANK 140110 (76), trimAl (77), and RAxML 8.2.9 (78). The phylogeny was visualized with the iTOL webserver (79). Identification of nodulation (nodABC) and nitrogenase genes (nifHDK) was performed with a published pipeline (73) reliant on the use of HMMER 3.1b2 (80), and the Pfam-A 31.0 (81) and TIGRFAM 15.0 (82) databases.

Data availability. Most sequencing data are available through the JGI Genome Portal (genome.jgi .doe.gov/portal/) under proposal 503835, as well as through the NCBI (for BioSample accession numbers, see Table S2 at doi.org/10.6084/m9.figshare.16556205). The data for stationary-phase cultures and bacteroids isolated from dnf mutant nodules are available only through the NCBI (BioProject accession no. PRJNA706182 and PRJNA705832; for BioSample accession numbers, see Table S2 at doi.org/10.6084/m9 .figshare.16556205). Raw flow cytometry FCS files are available as Data set S3 at doi.org/10.6084/m9 .figshare.16556205. All custom scripts to perform the analyses described in this study are available through GitHub (github.com/diCenzo-Lab/003_2021_Ensifer_DNA_methylation).

\section{ACKNOWLEDGMENTS}

We are grateful to E. Mullins (Teagasc, MTA2018233) for E. adhaerens OV14 and M. Bourge (I2BC) for help with the flow cytometry experiments.

Most sequencing work was performed at the U.S. Department of Energy (DOE) Joint Genome Institute (JGI), through the CSP New Investigator Program (proposal 503835). The work conducted by the U.S. Department of Energy Joint Genome Institute, a DOE Office of Science User Facility, is supported under contract no. DE-AC02-05CH11231. This work was partially supported by the "MICRO4Legumes" grant (Italian Ministry of Agriculture), by the grant "Dipartimento di Eccellenza 2018-2022" from the Italian Ministry of Education, University and Research (MIUR), and by a Discovery Grant from the Natural Sciences and Engineering Research Council of Canada. The present work benefited from the Imagerie-Gif core facility supported by the Agence Nationale de la Recherche (ANR-11-EQPX-0029/Morphoscope, ANR10-INBS-04/FranceBiolmaging, ANR-11-IDEX-0003-02/Saclay Plant Sciences). G.C.D. was supported by an NSERC postdoctoral fellowship and a European Molecular Biology Organization (EMBO) short-term fellowship for part of this work. L.C. was supported by the MICRO4Legumes grant (Italian Ministry of Agriculture). Q.N. was supported by a Ph.D. fellowship from the Paris-Saclay University. J.H.T.C. was supported by an NSERC Undergraduate Summer Research Award. P.M., E.G.B., and B.A. were supported by Saclay Plant Sciences (SPS) and grant ANR-17-CE20-0011 from the Agence Nationale de la Recherche.

\section{REFERENCES}

1. Greenberg MVC, Bourc'his D. 2019. The diverse roles of DNA methylation in mammalian development and disease. Nat Rev Mol Cell Biol 20: 590-607. https://doi.org/10.1038/s41580-019-0159-6.

2. Zhang H, Lang Z, Zhu J-K. 2018. Dynamics and function of DNA methylation in plants. Nat Rev Mol Cell Biol 19:489-506. https://doi.org/10.1038/ s41580-018-0016-z.

3. Tang Y, Gao X-D, Wang Y, Yuan B-F, Feng Y-Q. 2012. Widespread existence of cytosine methylation in yeast DNA measured by gas chromatography/mass spectrometry. Anal Chem 84:7249-7255. https://doi.org/10 .1021/ac301727c.

4. Blow MJ, Clark TA, Daum CG, Deutschbauer AM, Fomenkov A, Fries R, Froula J, Kang DD, Malmstrom RR, Morgan RD, Pósfai J, Singh K, Visel A, Wetmore K, Zhao Z, Rubin EM, Korlach J, Pennacchio LA, Roberts RJ. 2016. The epigenomic landscape of prokaryotes. PLoS Genet 12:e1005854. https://doi.org/10.1371/journal.pgen.1005854.

5. Sánchez-Romero MA, Cota I, Casadesús J. 2015. DNA methylation in bacteria: from the methyl group to the methylome. Curr Opin Microbiol 25: 9-16. https://doi.org/10.1016/j.mib.2015.03.004.

6. Gopalakrishnan S, Van Emburgh BO, Robertson KD. 2008. DNA methylation in development and human disease. Mutat Res 647:30-38. https://doi .org/10.1016/j.mrfmmm.2008.08.006.
7. Vasu K, Nagaraja V. 2013. Diverse functions of restriction-modification systems in addition to cellular defense. Microbiol Mol Biol Rev 77:53-72. https://doi.org/10.1128/MMBR.00044-12.

8. Atack JM, Tan A, Bakaletz LO, Jennings MP, Seib KL. 2018. Phasevarions of bacterial pathogens: methylomics sheds new light on old enemies. Trends Microbiol 26:715-726. https://doi.org/10.1016/j.tim.2018.01.008.

9. Adhikari S, Curtis PD. 2016. DNA methyltransferases and epigenetic regulation in bacteria. FEMS Microbiol Rev 40:575-591. https://doi.org/10.1093/ femsre/fuw023.

10. Campbell JL, Kleckner N. 1990. E. coli oriC and the dnaA gene promoter are sequestered from dam methyltransferase following the passage of the chromosomal replication fork. Cell 62:967-979. https://doi.org/10 .1016/0092-8674(90)90271-f.

11. Kang S, Lee H, Han JS, Hwang DS. 1999. Interaction of SeqA and Dam methylase on the hemimethylated origin of Escherichia coli chromosomal DNA replication. J Biol Chem 274:11463-11468. https://doi.org/10.1074/jbc.274.17.11463.

12. Lahue $R, A u$ K, Modrich P. 1989. DNA mismatch correction in a defined system. Science 245:160-164. https://doi.org/10.1126/science.2665076.

13. Zweiger G, Marczynski G, Shapiro L. 1994. A Caulobacter DNA methyltransferase that functions only in the predivisional cell. J Mol Biol 235: 472-485. https://doi.org/10.1006/jmbi.1994.1007.

14. Wright R, Stephens C, Shapiro L. 1997. The CcrM DNA methyltransferase is widespread in the alpha subdivision of proteobacteria, and its essential 
functions are conserved in Rhizobium meliloti and Caulobacter crescentus. Bacteriol 179:5869-5877. https://doi.org/10.1128/jb.179.18.5869-5877.1997.

15. Brilli M, Fondi M, Fani R, Mengoni A, Ferri L, Bazzicalupo M, Biondi EG. 2010. The diversity and evolution of cell cycle regulation in Alpha-proteobacteria: a comparative genomic analysis. BMC Syst Biol 4:52. https://doi .org/10.1186/1752-0509-4-52.

16. Kahng LS, Shapiro L. 2001. The CcrM DNA methyltransferase of Agrobacterium tumefaciens Is essential, and Its activity is cell cycle regulated. J Bacteriol 183:3065-3075. https://doi.org/10.1128/JB.183.10.3065-3075.2001.

17. Kozdon JB, Melfi MD, Luong K, Clark TA, Boitano M, Wang S, Zhou B, Gonzalez D, Collier J, Turner SW, Korlach J, Shapiro L, McAdams HH. 2013. Global methylation state at base-pair resolution of the Caulobacter genome throughout the cell cycle. Proc Natl Acad Sci U S A 110: E4658-E4667. https://doi.org/10.1073/pnas.1319315110.

18. Gonzalez D, Kozdon JB, McAdams HH, Shapiro L, Collier J. 2014. The functions of DNA methylation by CcrM in Caulobacter crescentus: a global approach. Nucleic Acids Res 42:3720-3735. https://doi.org/10.1093/nar/gkt1352.

19. Gonzalez D, Collier J. 2013. DNA methylation by CcrM activates the transcription of two genes required for the division of Caulobacter crescentus. Mol Microbiol 88:203-218. https://doi.org/10.1111/mmi.12180.

20. Fioravanti A, Fumeaux C, Mohapatra SS, Bompard C, Brilli M, Frandi A, Castric V, Villeret V, Viollier PH, Biondi EG. 2013. DNA binding of the cell cycle transcriptional regulator GcrA depends on N6-adenosine methylation in Caulobacter crescentus and other Alphaproteobacteria. PLoS Genet 9:e1003541. https://doi.org/10.1371/journal.pgen.1003541.

21. Wang ET, Young JPW. 2019. History of rhizobial taxonomy, p 23-39. In Wang ET, Tian CF, Chen WF, Young JPW, Chen WX (ed), Ecology and evolution of rhizobia: principles and applications. Springer, Singapore.

22. Oldroyd GED. 2013. Speak, friend, and enter: signalling systems that promote beneficial symbiotic associations in plants. Nat Rev Microbiol 11: 252-263. https://doi.org/10.1038/nrmicro2990.

23. Barnett MJ, Toman CJ, Fisher RF, Long SR. 2004. A dual-genome Symbiosis Chip for coordinate study of signal exchange and development in a prokaryote-host interaction. Proc Natl Acad Sci U S A 101:16636-16641. https://doi.org/10.1073/pnas.0407269101

24. Roux B, Rodde N, Jardinaud M-F, Timmers T, Sauviac L, Cottret L, Carrère S, Sallet E, Courcelle E, Moreau S, Debellé F, Capela D, de Carvalho-Niebel F, Gouzy J, Bruand C, Gamas P. 2014. An integrated analysis of plant and bacterial gene expression in symbiotic root nodules using laser-capture microdissection coupled to RNA sequencing. Plant J 77:817-837. https:// doi.org/10.1111/tpj.12442.

25. diCenzo GC, Tesi M, Pfau T, Mengoni A, Fondi M. 2020. Genome-scale metabolic reconstruction of the symbiosis between a leguminous plant and a nitrogen-fixing bacterium. Nat Commun 11:2574. https://doi.org/ 10.1038/s41467-020-16484-2.

26. Mergaert $P$, Uchiumi T, Alunni B, Evanno G, Cheron A, Catrice O, Mausset A-E, Barloy-Hubler F, Galibert F, Kondorosi A, Kondorosi E. 2006. Eukaryotic control on bacterial cell cycle and differentiation in the Rhizobium-legume symbiosis. Proc Natl Acad Sci U S A 103:5230-5235. https://doi.org/ 10.1073/pnas.0600912103.

27. Czernic P, Gully D, Cartieaux F, Moulin L, Guefrachi I, Patrel D, Pierre O, Fardoux J, Chaintreuil C, Nguyen P, Gressent F, Da Silva C, Poulain J, Wincker P, Rofidal V, Hem S, Barrière Q, Arrighi J-F, Mergaert P, Giraud E. 2015. Convergent evolution of endosymbiont differentiation in dalbergioid and inverted repeat-lacking clade legumes mediated by nodulespecific cysteine-rich peptides. Plant Physiol 169:1254-1265. https://doi .org/10.1104/pp.15.00584.

28. Pini F, Frage B, Ferri L, De Nisco NJ, Mohapatra SS, Taddei L, Fioravanti A, Dewitte F, Galardini M, Brilli M, Villeret V, Bazzicalupo M, Mengoni A, Walker GC, Becker A, Biondi EG. 2013. The DivJ, CbrA and PleC system controls DivK phosphorylation and symbiosis in Sinorhizobium meliloti. Mol Microbiol 90:54-71. https://doi.org/10.1111/mmi.12347.

29. Kobayashi H, De Nisco NJ, Chien P, Simmons LA, Walker GC. 2009. Sinorhizobium meliloti CpdR1 is critical for co-ordinating cell cycle progression and the symbiotic chronic infection. Mol Microbiol 73:586-600. https:// doi.org/10.1111/j.1365-2958.2009.06794.x.

30. Pini F, De Nisco NJ, Ferri L, Penterman J, Fioravanti A, Brilli M, Mengoni A, Bazzicalupo M, Viollier PH, Walker GC, Biondi EG. 2015. Cell cycle control by the master regulator CtrA in Sinorhizobium meliloti. PLoS Genet 11: e1005232. https://doi.org/10.1371/journal.pgen.1005232.

31. Gibson KE, Campbell GR, Lloret J, Walker GC. 2006. CbrA is a stationaryphase regulator of cell surface physiology and legume symbiosis in Sinorhizobium meliloti. J Bacteriol 188:4508-4521. https://doi.org/10.1128/ JB.01923-05.
32. Van de Velde W, Zehirov G, Szatmari A, Debreczeny M, Ishihara H, Kevei Z, Farkas A, Mikulass K, Nagy A, Tiricz H, Satiat-Jeunemaître B, Alunni B, Bourge M, Kucho K, Abe M, Kereszt A, Maróti G, Uchiumi T, Kondorosi E, Mergaert P. 2010. Plant peptides govern terminal differentiation of bacteria in symbiosis. Science 327:1122-1126. https://doi.org/10.1126/science.1184057.

33. Penterman J, Abo RP, De Nisco NJ, Arnold MFF, Longhi R, Zanda M, Walker GC. 2014. Host plant peptides elicit a transcriptional response to control the Sinorhizobium meliloti cell cycle during symbiosis. Proc Natl Acad Sci U S A 111:3561-3566. https://doi.org/10.1073/pnas.1400450111.

34. Farkas A, Maróti G, Dürgő H, Györgypál Z, Lima RM, Medzihradszky KF, Kereszt A, Mergaert P, Kondorosi E. 2014. Medicago truncatula symbiotic peptide NCR247 contributes to bacteroid differentiation through multiple mechanisms. Proc Natl Acad Sci U S A 111:5183-5188. https://doi.org/ 10.1073/pnas.1404169111.

35. Satgé C, Moreau S, Sallet E, Lefort G, Auriac M-C, Remblière C, Cottret L, Gallardo K, Noirot C, Jardinaud M-F, Gamas P. 2016. Reprogramming of DNA methylation is critical for nodule development in Medicago truncatula. Nat Plants 2:16166. https://doi.org/10.1038/nplants.2016.166.

36. Nagymihály $M$, Veluchamy A, Györgypál $Z$, Ariel $F$, Jégu T, Benhamed $M$, Szúcs A, Kereszt A, Mergaert P, Kondorosi É. 2017. Ploidy-dependent changes in the epigenome of symbiotic cells correlate with specific patterns of gene expression. Proc Natl Acad Sci U S A 114:4543-4548. https://doi.org/10.1073/pnas.1704211114.

37. Pecrix $Y$, Staton $S E$, Sallet $E$, Lelandais-Brière $C$, Moreau $S$, Carrère $S$, Blein T, Jardinaud M-F, Latrasse D, Zouine M, Zahm M, Kreplak J, Mayjonade B, Satgé C, Perez M, Cauet S, Marande W, Chantry-Darmon C, Lopez-Roques $C$, Bouchez $O$, Bérard $A$, Debellé $F$, Muños $S$, Bendahmane $A$, Bergès $H$, Niebel A, Buitink J, Frugier F, Benhamed M, Crespi M, Gouzy J, Gamas P. 2018. Whole-genome landscape of Medicago truncatula symbiotic genes. Nat Plants 4:1017-1025. https://doi.org/10.1038/s41477-018-0286-7.

38. Davis-Richardson AG, Russell JT, Dias R, McKinlay AJ, Canepa R, Fagen JR, Rusoff KT, Drew JC, Kolaczkowski B, Emerich DW, Triplett EW. 2016. Integrating DNA methylation and gene expression data in the development of the soybean-Bradyrhizobium $\mathrm{N}_{2}$-fixing symbiosis. Front Microbiol 7: 518. https://doi.org/10.3389/fmicb.2016.00518.

39. Barrière Q, Guefrachi I, Gully D, Lamouche F, Pierre O, Fardoux J, Chaintreuil C, Alunni B, Timchenko T, Giraud E, Mergaert P. 2017. Integrated roles of BclA and DD-carboxypeptidase 1 in Bradyrhizobium differentiation within NCR-producing and NCR-lacking root nodules. Sci Rep 7:9063. https://doi.org/10.1038/ s41598-017-08830-0.

40. diCenzo GC, Zamani M, Checcucci A, Fondi M, Griffitts J, Finan TM, Mengoni A. 2019. Multidisciplinary approaches for studying rhizobium-legume symbioses. Can J Microbiol 65:1-33. https://doi.org/10.1139/cjm-2018-0377.

41. diCenzo GC, Muhammed Z, Østerås M, O’Brien SAP, Finan TM. 2017. A key regulator of the glycolytic and gluconeogenic central metabolic pathways in Sinorhizobium meliloti. Genetics 207:961-974. https://doi.org/10 .1534/genetics.117.300212.

42. diCenzo GC, MacLean AM, Milunovic B, Golding GB, Finan TM. 2014. Examination of prokaryotic multipartite genome evolution through experimental genome reduction. PLoS Genet 10:e1004742. https://doi.org/10 .1371/journal.pgen.1004742.

43. Mohapatra SS, Fioravanti A, Biondi EG. 2014. DNA methylation in Caulobacter and other Alphaproteobacteria during cell cycle progression. Trends Microbiol 22:528-535. https://doi.org/10.1016/j.tim.2014.05.003.

44. Nouri H, Monnier A-F, Fossum-Raunehaug S, Maciag-Dorszynska M, Cabin-Flaman A, Képès $F$, Wegrzyn G, Szalewska-Palasz A, Norris V, Skarstad K, Janniere L. 2018. Multiple links connect central carbon metabolism to DNA replication initiation and elongation in Bacillus subtilis. DNA Res 25:641-653. https://doi.org/10.1093/dnares/dsy031.

45. De Nisco NJ, Abo RP, Wu CM, Penterman J, Walker GC. 2014. Global analysis of cell cycle gene expression of the legume symbiont Sinorhizobium meliloti. Proc Natl Acad Sci U S A 111:3217-3224. https://doi.org/10.1073/ pnas. 1400421111.

46. Adhikari S, Erill I, Curtis PD. 2021. Transcriptional rewiring of the GcrA/ CcrM bacterial epigenetic regulatory system in closely related bacteria. PLoS Genet 17:e1009433. https://doi.org/10.1371/journal.pgen.1009433.

47. Fagorzi C, Ilie A, Decorosi F, Cangioli L, Viti C, Mengoni A, diCenzo GC. 2020. Symbiotic and nonsymbiotic members of the genus Ensifer (syn. Sinorhizobium) are separated into two clades based on comparative genomics and high-throughput phenotyping. Genome Biol Evol 12: 2521-2534. https://doi.org/10.1093/gbe/evaa221.

48. Moreau D, Voisin A-S, Salon C, Munier-Jolain N. 2008. The model symbiotic association between Medicago truncatula cv. Jemalong and Rhizobium meliloti strain 2011 leads to N-stressed plants when symbiotic N2 
fixation is the main $\mathrm{N}$ source for plant growth. J Exp Bot 59:3509-3522. https://doi.org/10.1093/jxb/ern203.

49. Kazmierczak T, Nagymihaly M, Lamouche F, Barrière Q, Guefrachi I, Alunn B, Ouadghiri M, Ibijbijen J, Kondorosi E, Mergaert P, Gruber V. 2017. Specific host-responsive associations between Medicago truncatula accessions and Sinorhizobium strains. Mol Plant Microbe Interact 30:399-409. https://doi.org/10.1094/MPMI-01-17-0009-R.

50. Vasse J, De Billy F, Camut S, Truchet G. 1990. Correlation between ultrastructural differentiation of bacteroids and nitrogen fixation in alfalfa nodules. J Bacteriol 172:4295-4306. https://doi.org/10.1128/jb.172.8.4295-4306.1990.

51. Starker CG, Parra-Colmenares AL, Smith L, Mitra RM, Long SR. 2006. Nitrogen fixation mutants of Medicago truncatula fail to support plant and bacterial symbiotic gene expression. Plant Physiol 140:671-680. https://doi .org/10.1104/pp.105.072132.

52. Wang D, Griffitts J, Starker C, Fedorova E, Limpens E, Ivanov S, Bisseling T, Long S. 2010. A nodule-specific protein secretory pathway required for nitrogen-fixing symbiosis. Science 327:1126-1129. https://doi.org/10.1126/science .1184096.

53. Bourcy M, Brocard L, Pislariu Cl, Cosson V, Mergaert P, Tadege M, Mysore KS, Udvardi MK, Gourion B, Ratet P. 2013. Medicago truncatula DNF2 is a PI-PLC-XD-containing protein required for bacteroid persistence and prevention of nodule early senescence and defense-like reactions. New Phytol 197:1250-1261. https://doi.org/10.1111/nph.12091.

54. Kim M, Chen Y, Xi J, Waters C, Chen R, Wang D. 2015. An antimicrobial peptide essential for bacterial survival in the nitrogen-fixing symbiosis. Proc Natl Acad Sci U S A 112:15238-15243. https://doi.org/10.1073/pnas.1500123112.

55. Domonkos A, Horvath B, Marsh JF, Halasz G, Ayaydin F, Oldroyd GED, Kalo P. 2013. The identification of novel loci required for appropriate nodule development in Medicago truncatula. BMC Plant Biol 13:157. https://doi .org/10.1186/1471-2229-13-157.

56. Horváth B, Domonkos Á, Kereszt A, Szücs A, Ábrahám E, Ayaydin F, Bóka K, Chen Y, Chen R, Murray JD, Udvardi MK, Kondorosi É, Kaló P. 2015. Loss of the nodule-specific cysteine rich peptide, NCR169, abolishes symbiotic nitrogen fixation in the Medicago truncatula dnf7 mutant. Proc Natl Acad Sci U S A 112:15232-15237. https://doi.org/10.1073/pnas.1500777112.

57. Lang C, Long SR. 2015. Transcriptomic analysis of Sinorhizobium meliloti and Medicago truncatula symbiosis using nitrogen fixation-deficient nodules. Mol Plant Microbe Interact 28:856-868. https://doi.org/10.1094/ MPMI-12-14-0407-R.

58. Ferri L, Gori A, Biondi EG, Mengoni A, Bazzicalupo M. 2010. Plasmid electroporation of Sinorhizobium strains: the role of the restriction gene $h s d R$ in type strain Rm1021. Plasmid 63:128-135. https://doi.org/10.1016/j.plasmid 2010.01.001.

59. Brumwell SL, MacLeod MR, Huang T, Cochrane RR, Meaney RS, Zamani M, Matysiakiewicz O, Dan KN, Janakirama P, Edgell DR, Charles TC, Finan TM, Karas BJ. 2019. Designer Sinorhizobium meliloti strains and multi-functional vectors enable direct inter-kingdom DNA transfer. PLoS One 14: e0206781. https://doi.org/10.1371/journal.pone.0206781.

60. Bhagwat AS, Lieb M. 2002. Cooperation and competition in mismatch repair: very short-patch repair and methyl-directed mismatch repair in Escherichia coli. Mol Microbiol 44:1421-1428. https://doi.org/10.1046/j .1365-2958.2002.02989.x.

61. Haakonsen DL, Yuan AH, Laub MT. 2015. The bacterial cell cycle regulator GcrA is a $\sigma^{70}$ cofactor that drives gene expression from a subset of methylated promoters. Genes Dev 29:2272-2286. https://doi.org/10.1101/gad 270660.115

62. Wright R, Stephens C, Zweiger G, Shapiro L, Alley MR. 1996. Caulobacter Lon protease has a critical role in cell-cycle control of DNA methylation. Genes Dev 10:1532-1542. https://doi.org/10.1101/gad.10.12.1532.

63. Cevallos MA, Cervantes-Rivera R, Gutiérrez-Ríos RM. 2008. The repABC plasmid family. Plasmid 60:19-37. https://doi.org/10.1016/j.plasmid.2008.03.001.

64. Fournes F, Val M-E, Skovgaard O, Mazel D. 2018. Replicate once per cell cycle: replication control of secondary chromosomes. Front Microbiol 9: 1833. https://doi.org/10.3389/fmicb.2018.01833.

65. Frage B, Döhlemann J, Robledo M, Lucena D, Sobetzko P, Graumann PL, Becker A. 2016. Spatiotemporal choreography of chromosome and megaplasmids in the Sinorhizobium meliloti cell cycle. Mol Microbiol 100: 808-823. https://doi.org/10.1111/mmi.13351.

66. Rasmussen T, Jensen RB, Skovgaard O. 2007. The two chromosomes of Vibrio cholerae are initiated at different time points in the cell cycle. EMBO J 26:3124-3131. https://doi.org/10.1038/sj.emboj.7601747.

67. Krall L, Wiedemann U, Unsin G, Weiss S, Domke N, Baron C. 2002. Detergent extraction identifies different VirB protein subassemblies of the type IV secretion machinery in the membranes of Agrobacterium tumefaciens. Proc Natl Acad Sci U S A 99:11405-11410. https://doi.org/10.1073/pnas.172390699.

68. Cowie A, Cheng J, Sibley CD, Fong Y, Zaheer R, Patten CL, Morton RM, Golding GB, Finan TM. 2006. An integrated approach to functional genomics: construction of a novel reporter gene fusion library for Sinorhizobium meliloti. Appl Environ Microbiol 72:7156-7167. https://doi.org/10 .1128/AEM.01397-06

69. Eid J, Fehr A, Gray J, Luong K, Lyle J, Otto G, Peluso P, Rank D, Baybayan P, Bettman B, Bibillo A, Bjornson K, Chaudhuri B, Christians F, Cicero R, Clark S, Dalal R, deWinter A, Dixon J, Foquet M, Gaertner A, Hardenbol P, Heiner C, Hester K, Holden D, Kearns G, Kong X, Kuse R, Lacroix $Y$, Lin S, Lundquist $P$, Ma C, Marks P, Maxham M, Murphy D, Park I, Pham T, Phillips M, Roy J, Sebra R, Shen G, Sorenson J, Tomaney A, Travers K, Trulson M, Vieceli J, Wegener J, Wu D, Yang A, Zaccarin D, et al. 2009. Real-time DNA sequencing from single polymerase molecules. Science 323:133-138. https://doi.org/10.1126/science.1162986.

70. Chaisson MJ, Tesler G. 2012. Mapping single molecule sequencing reads using basic local alignment with successive refinement (BLASR): application and theory. BMC Bioinform 13:238. https://doi.org/10.1186/1471-2105-13-238.

71. Flusberg BA, Webster DR, Lee JH, Travers KJ, Olivares EC, Clark TA, Korlach J, Turner SW. 2010. Direct detection of DNA methylation during singlemolecule, real-time sequencing. Nat Methods 7:461-465. https://doi.org/ 10.1038/nmeth.1459.

72. Clark TA, Murray IA, Morgan RD, Kislyuk AO, Spittle KE, Boitano M, Fomenkov A, Roberts RJ, Korlach J. 2012. Characterization of DNA methyltransferase specificities using single-molecule, real-time DNA sequencing. Nucleic Acids Res 40:e29. https://doi.org/10.1093/nar/gkr1146.

73. diCenzo GC, Debiec K, Krzysztoforski J, Uhrynowski W, Mengoni A, Fagorzi C, Gorecki A, Dziewit L, Bajda T, Rzepa G, Drewniak L. 2018. Genomic and biotechnological characterization of the heavy-metal resistant, arsenic-oxidizing bacterium Ensifer sp. M14. Genes 9:379. https://doi .org/10.3390/genes9080379.

74. Page AJ, Cummins CA, Hunt M, Wong VK, Reuter S, Holden MTG, Fookes M, Falush D, Keane JA, Parkhill J. 2015. Roary: rapid large-scale prokaryote pan genome analysis. Bioinformatics 31:3691-3693. https://doi.org/10 .1093/bioinformatics/btv421.

75. Seemann T. 2014. Prokka: rapid prokaryotic genome annotation. Bioinformatics 30:2068-2069. https://doi.org/10.1093/bioinformatics/btu153.

76. Löytynoja A. 2014. Phylogeny-aware alignment with PRANK, p 155-170. In Russell D (ed), Methods in molecular biology (methods and protocols). Humana Press, Totowa, NJ.

77. Capella-Gutiérrez S, Silla-Martínez JM, Gabaldón T. 2009. trimAl: a tool for automated alignment trimming in large-scale phylogenetic analyses. Bioinformatics 25:1972-1973. https://doi.org/10.1093/bioinformatics/btp348.

78. Stamatakis A. 2014. RAxML version 8: a tool for phylogenetic analysis and post-analysis of large phylogenies. Bioinformatics 30:1312-1313. https:// doi.org/10.1093/bioinformatics/btu033.

79. Letunic I, Bork P. 2016. Interactive tree of life (iTOL) v3: an online tool for the display and annotation of phylogenetic and other trees. Nucleic Acids Res 44:W242-W245. https://doi.org/10.1093/nar/gkw290.

80. Eddy SR. 2009. A new generation of homology search tools based on probabilistic inference. Genome Inform 23:205-211.

81. Finn RD, Coggill P, Eberhardt RY, Eddy SR, Mistry J, Mitchell AL, Potter SC, Punta M, Qureshi M, Sangrador-Vegas A, Salazar GA, Tate J, Bateman A. 2016. The Pfam protein families database: towards a more sustainable future. Nucleic Acids Res 44:D279-D285. https://doi.org/10.1093/nar/gkv1344.

82. Haft DH, Selengut JD, Richter RA, Harkins D, Basu MK, Beck E. 2013. TIGRFAMs and genome properties in 2013. Nucleic Acids Res 41:D387-D395. https://doi.org/10.1093/nar/gks1234. 